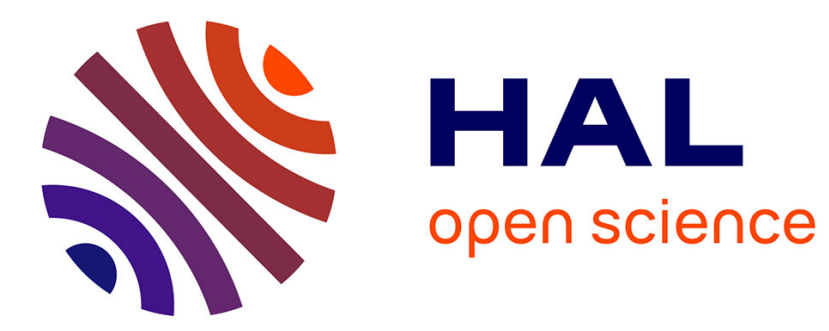

\title{
Pharmacokinetic/pharmacodynamic modelling of robenacoxib in a feline tissue cage model of inflammation
}

Ludovic Pelligand, Jonathan King, Pierre-Louis Toutain, Jonathan Elliott, Peter Lees

\section{- To cite this version:}

Ludovic Pelligand, Jonathan King, Pierre-Louis Toutain, Jonathan Elliott, Peter Lees. Pharmacokinetic/pharmacodynamic modelling of robenacoxib in a feline tissue cage model of inflammation. Journal of Veterinary Pharmacology and Therapeutics, 2012, 35 (1), pp.19-32. 10.1111/j.13652885.2011.01288.x . hal-01191246

\section{HAL Id: hal-01191246 \\ https://hal.science/hal-01191246}

Submitted on 1 Sep 2015

HAL is a multi-disciplinary open access archive for the deposit and dissemination of scientific research documents, whether they are published or not. The documents may come from teaching and research institutions in France or abroad, or from public or private research centers.
L'archive ouverte pluridisciplinaire HAL, est destinée au dépôt et à la diffusion de documents scientifiques de niveau recherche, publiés ou non, émanant des établissements d'enseignement et de recherche français ou étrangers, des laboratoires publics ou privés. 


\section{Pharmacokinetic/pharmacodynamic modelling of robenacoxib in a feline tissue cage model of inflammation}

L. PELLIGAND*

J. N. KING ${ }^{\dagger}$

P. L. TOUTAIN

J. ELLIOTT* \&

P. LEES*

*Royal Veterinary College, Department of Veterinary Basic Sciences, Hatfield, Herts, UK; ${ }^{\dagger}$ Novartis Animal Health Inc., Clinical Development, Basel, Switzerland; ${ }^{\star}$ Ecole Nationale Vétérinaire de Toulouse, Physiopathologie et Toxicologie Experimentales, Toulouse, France
Pelligand, L., King, J. N., Toutain, P. L., Elliott, J., Lees, P. Pharmacokinetic/pharmacodynamic modelling of robenacoxib in a feline tissue cage model of inflammation. J. vet. Pharmacol. Therap. 35, 19-32.

Robenacoxib is a novel nonsteroidal anti-inflammatory drug developed for use in cats. It is a highly selective COX-2 inhibitor. Results from previous feline studies showed that, despite a short half-life in blood, the effect of robenacoxib persisted for $24 \mathrm{~h}$ in clinical studies. A tissue cage model of acute inflammation was used to determine robenacoxib's pharmacokinetics and its ex vivo and in vivo selectivity for COX-1 and COX-2 using serum $\mathrm{TxB}_{2}$ and exudate $\mathrm{PGE}_{2}$ as surrogate markers for enzyme activity, respectively. After intravenous, subcutaneous and oral administration $(2 \mathrm{mg} / \mathrm{kg})$, the clearance of robenacoxib from blood was rapid $(0.54-0.71 \mathrm{~L} \cdot \mathrm{h} / \mathrm{kg})$. The mean residence time (MRT) in blood was short $(0.4,1.9$ and $3.3 \mathrm{~h}$ after intravenous, subcutaneous and oral administration, respectively), but in exudate MRT was approximately $24 \mathrm{~h}$ regardless of the route of administration. Robenacoxib inhibition of COX-1 in blood was transient, occurring only at high concentrations, but inhibition of COX-2 in exudate persisted to $24 \mathrm{~h}$. The potency ratio $\left(\mathrm{IC}_{50} \mathrm{COX}-1\right.$ : $\left.\mathrm{IC}_{50} \mathrm{COX}-2\right)$ was 171:1, and slopes of the concentration-effect relationship were 1.36 and 1.12 for COX-1 and COX-2, respectively. These data highlight the enzymatic selectivity and inflamed tissue selectivity of robenacoxib and support the current recommendation of once-daily administration.

(Paper received 1 October 2010; accepted for publication 2 February 2011)

L. Pelligand, Royal Veterinary College, Hawkshead Campus, Hatfield, Hertfordshire AL97TA, UK. E-mail: lpelligand@rvc.ac.uk

\section{INTRODUCTION}

Conditions requiring analgesia, such as osteoarthritis and postoperative pain, are becoming increasingly recognized and diagnosed in the cat (Taylor \& Robertson, 2004; Lascelles, 2010). Analgesics of various classes are used to alleviate pain, and the use of nonsteroidal anti-inflammatory drugs (NSAIDs) in small animal practice has increased dramatically during the last 20 years (Lascelles et al., 2007). The safety of many NSAIDs in cats, such as salicylate, is relatively poor and at least for some drugs appears to be related to prolonged half-lives resulting in long exposure times (Lascelles et al., 2007). Due to the high prevalence of kidney disease in the cat (Elliott \& Barber, 1998) and the importance of prostaglandins in renal homoeostasis, the risk of renal injury with NSAIDs is of particular concern in this species. New COX-1-sparing NSAIDs (COXibs) should, in principle, provide advantages over older nonselective NSAIDs for use in the cat.

Robenacoxib is a recently approved highly selective COX-2 inhibitor licensed for use in cats and dogs (Jung et al., 2009).
Determination of the dosage regimen for this drug has benefited from the pharmacokinetic-pharmacodynamic (PK-PD) modelling approach (Giraudel et al., 2009a), together with clinical studies (Giraudel et al., 2010). Robenacoxib is registered in the EU to be given once daily, either by the subcutaneous route at a dosage of $2 \mathrm{mg} / \mathrm{kg}$ or by the oral route at a dosage of 1 to $2.4 \mathrm{mg} / \mathrm{kg}$ for up to 6 days.

The PK of robenacoxib has been established in the cat after intravenous, subcutaneous and oral administration (J.N. King, M. Jung, M.P. Maurer, W. Seewald, V. Schmid \& P. Lees, unpublished data). The reported elimination half-life after subcutaneous injection was $1.1 \mathrm{~h}$, as the drug is rapidly cleared from the blood. The dosage predictions based on the results from a kaolin model of inflammation (Giraudel et al., 2005a, 2009a) suggested twice-daily dosing in preference to once daily for maintenance of clinical effect throughout the 24-h period. However, the analgesic effect of robenacoxib persisted over the entire 24-h dosage interval with once-daily dosing in field studies, including placebo-controlled and noninferiority studies using meloxicam and ketoprofen as 
positive controls (Giraudel et al., 2010; J.M. Giraudel, J.N. King, D. Alexander, W. Seewald \& P. Gruet, unpublished data). We hypothesized that despite its short half-life in blood, robenacoxib would persist and be effective for longer at sites of inflammation, thus accounting for the long-lasting analgesic effect. Persistence in deep peripheral compartments could be attributed to protein binding and tissue affinity. Tissue cage models have enabled intensive sequential sampling on the same individual for the characterization of concentration-time and concentration-effect profiles of anti-inflammatory drugs in inflamed tissues and blood (Sidhu et al., 2003). The model was recently adapted and validated in the cat (Pelligand et al., 2011). The aim of this study was to describe the PK and PD of robenacoxib in a feline model of sterile inflammation. Specific objectives were (i) to establish the magnitude and time course of robenacoxib penetration into an acute inflammatory site after intravenous, subcutaneous and oral dosing and (ii) to determine the magnitude and time course of inhibition of ex vivo serum $\mathrm{TxB}_{2}$ formation and in vivo production of exudate $\mathrm{PGE}_{2}$, as indicators of COX-1 and COX-2 inhibition, respectively.

\section{MATERIALS AND METHODS}

\section{Animals and instrumentation}

Eight domestic short haired cats were used for a first cross-over study including two periods (four males, four females, mean weight $3.5 \pm 0.42 \mathrm{~kg}$, mean age 2.7 years old). Nine cats were used in a second cross-over study including three periods (four males, five females, $3.8 \pm 0.31 \mathrm{~kg}$, mean age 1.2 years old). The cats were group-housed, except during the sampling weeks when they were individually housed. The cats were fed dried food twice each day and water was available ad libitum. The cats were trained daily for socialization and acceptance of the sampling procedure. All animals remained in good health during the studies and were re-homed at the end of the study. The study complied with United Kingdom Home Office regulations and was approved by the Royal Veterinary College Ethics and Welfare Committee.

Four tissue cages were surgically implanted in each cat as described previously (Pelligand et al., 2011). They were flushed with sterile saline under general anaesthesia 7 weeks after implantation in experiment 2. At the end of the study, all tissue cages were electively removed under general anaesthesia between 9 and 10 months after implantation, before the cats were re-homed.

On the day before intracaveal carrageenan injection, a double lumen catheter (CS15402E; Arrow International UK Ltd, Uxbridge, UK) was inserted in a jugular vein under general anaesthesia in each cat to facilitate drug administration and blood sampling. Both lumens were cleared of air and flushed with a $0.9 \%$ sterile saline solution containing $1 \mathrm{IU} / \mathrm{mL}$ of heparin (Multiparin $1000 \mathrm{UI} / \mathrm{mL}$; Wockhardt UK Ltd, Wrexham, UK). Before recovery from anaesthesia, the skin surface over $5 \mathrm{~cm}$ around a single carrageenan-naïve tissue cage was clipped and surgically prepared. An Elizabethan collar and a light neck bandage were placed and removed after the last sample had been taken (120 h).

\section{Tissue cage stimulation and sampling}

On the same day preceding the carrageenan injection, aliquots of a $2 \%$ carrageenan solution (Viscarin; FMC biopolymers, Philadelphia, PA, USA) were prepared and sterilized at $121{ }^{\circ} \mathrm{C}$ for $15 \mathrm{~min}$ in an autoclave (Pelligand et al., 2011). A previously unused tissue cage (carrageenan-naïve) was used for each period so that no tissue cage received carrageenan on more than one single occasion. At the beginning of each period of the study, $1 \mathrm{~mL}$ of carrageenan $2 \%$ solution was injected in a single tissue cage for each individual cat (Pelligand et al., 2011). The same stimulated tissue cage was subsequently sampled to obtain 1.0$1.3 \mathrm{~mL}$ of exudate from the same cat at all of the following time points: 3 (experiment 2 only), 6, 9, 12, 24, 34, 48, 72, 96 and $120 \mathrm{~h}$ after carrageenan injection. Exudate samples were transferred into 1.5-mL Eppendorf tubes containing $10 \mu \mathrm{g}$ of indomethacin (Product I7378; Sigma, Poole, UK) to prevent ex vivo eicosanoid generation. The tube was mixed by gentle inversion and placed on ice until centrifugation at $1000 \mathrm{~g}, 4^{\circ} \mathrm{C}$ for $10 \mathrm{~min}$. The supernatant was aliquoted and frozen at $-80^{\circ} \mathrm{C}$.

\section{Drug allocation, dosing and sampling schedule}

Experiment 1 was a two-period cross-over study, and experiment 2 was a three-period cross-over study. A 28-day washout interval was allowed between each period. The cats were weighed on the day prior to treatment administration. The treatment for the first period was randomly allocated and the sequence of treatments for the subsequent periods followed a latin square design. For experiment 1, robenacoxib $2 \mathrm{mg} / \mathrm{kg}$ intravenously once (Onsior $20 \mathrm{mg} / \mathrm{mL}$ solution for injection; Novartis Animal Health, Basel, Switzerland) and the excipient solution without active drug were used for the treatments. The proximal lumen of the catheter was used for intravenous administration, flushed and sealed thereafter. For experiment 2 , $2 \mathrm{mg} / \mathrm{kg}$ robenacoxib subcutaneously, $6 \mathrm{mg}$ robenacoxib orally (Onsior 6 mg flavoured tablets; Novartis Animal Health) or the oral formulation without active substance were used for the treatments. The morning meal was withheld until $2 \mathrm{~h}$ after administration of treatments, and the evening meal was given after the last sample of the day.

Blood samples (maximum $1.5 \mathrm{~mL}$ ) were taken from the distal lumen of the catheter pre-injection and at 4, 15, $30 \mathrm{~min}, 1,1.5$, $2,3,4,6,9,12$ and $24 \mathrm{~h}$ after injection. To avoid contamination of the samples with flush solution, $1.5 \mathrm{~mL}$ of blood was withdrawn in a syringe containing $0.5 \mathrm{~mL}$ of heparinized $0.9 \%$ saline solution before taking the blood sample. After sampling, the blood in the first syringe was re-injected through the distal port of the catheter which was then flushed with $2 \mathrm{~mL}$ heparinized $0.9 \%$ saline solution $(1 \mathrm{IU} / \mathrm{mL})$. Actual sampling times were recorded. An aliquot of $0.2 \mathrm{~mL}$ blood was allowed to 
clot in glass vials (03-FIVS; Chromacol, Welwyn Garden City, UK) whilst incubated in a water bath at $37^{\circ} \mathrm{C}$ for $1 \mathrm{~h}$ and then placed on ice for $<1 \mathrm{~h}$. After centrifugation $\left(1500 \mathrm{~g}, 4^{\circ} \mathrm{C}\right.$, $10 \mathrm{~min})$, the supernatant was transferred into Eppendorf tubes and stored at $-80{ }^{\circ} \mathrm{C}$. The rest of the blood was transferred to $1.3 \mathrm{~mL}$ EDTA tubes (International Scientific Supplies Ltd, Bradford, UK) and stored at $-80{ }^{\circ} \mathrm{C}$.

\section{Robenacoxib and prostanoid measurements}

Robenacoxib concentrations were measured using a sensitive analytical method validated under GLP, as described previously in dog blood and plasma and cat whole blood (Jung et al., 2009). Briefly, the method involved an initial analysis by HPLC-UV covering the range of $500-20000 \mathrm{ng} / \mathrm{mL}$ and, if required, a subsequent analysis by LC-MS covering the range of 3-100 ng/mL for blood. The same method was used for exudate, except that $250 \mu \mathrm{L}$ of sample was extracted and diluted twofold with water, instead of using $500 \mu \mathrm{L}$ of sample as for blood. The appropriate matrix (blank blood or blank exudate) was used to determine, separately, the standard curves and for quality control for blood and exudate. For blood, the lower and upper limits of quantification were 3 and $100 \mathrm{ng} / \mathrm{mL}$ for the LC-MS measurements, respectively. As the exudate was diluted twofold, the MS method had a range of $6-200 \mathrm{ng} / \mathrm{mL}$ for exudate in the initial method validation, but this was extended subsequently to 3.5-200 $\mathrm{ng} / \mathrm{mL}$ because it was established during the analysis that reliable results were obtained at the lower end of the range.

Exudate $\mathrm{PGE}_{2}$ concentrations were measured with competitive radio-immunoassay (RIA) (Pelligand et al., 2011), adapted from the method of Higgins and Lees (1984). Serum $\mathrm{TxB}_{2}$ measurements were made by RIA on blood allowed to clot in glass tubes for $1 \mathrm{~h}$ at $37^{\circ} \mathrm{C}$ (Higgins \& Lees, 1984). At least two concentrations of pooled samples were aliquoted and used as quality controls. They were dispersed over the sequences of unknown samples to calculate inter- and intra-assay variability.

\section{Robenacoxib pharmacokinetic calculations}

Pharmacokinetics and PK-PD modelling were performed by the least-squares regression method using WinNonlin professional software (WinNonlin version 5.2, Pharsight Corporation, Mountain View, CA, USA). Blood robenacoxib concentrations $C(t)$ were fitted for each cat using an equation corresponding to drug disposition in a two-compartmental model without an absorption phase (intravenous administration, as in equation 1), a two-compartmental model with an absorption phase (subcutaneous administration, as in equation 2) or a monocompartmental model with an absorption phase (oral administration, as in equation 3):

$$
\begin{gathered}
C(t)=Y_{1} e^{-\lambda_{1} t}+Y_{2} e^{-\lambda_{2} t} \\
C(t)=-\left(Y_{1}+Y_{2}\right) e^{-k_{a} t}+Y_{1} e^{-\lambda_{1} t}+Y_{2} e^{-\lambda_{2} t} \\
C(t)=Y_{1}\left(e^{-\lambda_{1} t}-e^{-k_{a} t}\right)
\end{gathered}
$$

where $\lambda_{1}$ and $\lambda_{2}$ are the initial and terminal slopes and $Y_{1}$ and $Y_{2}$ the intercepts on the $Y$ axis when $C(t)$ is plotted on a semi-logarithmic scale and $k_{\mathrm{a}}$ is the first-order absorption rate constant. Data were weighted by the reciprocal of the squared-estimated value for blood concentrations after intravenous administration and by the reciprocal of the estimated value for blood concentration after subcutaneous or oral administration. Goodness of fit and selection of the appropriate model were evaluated using the Akaike Information Criterion estimate (Yamaoka et al., 1978) and by visual inspection of the fitted curves and residuals.

Exudate concentrations $C_{\mathrm{e}}(t)$ were fitted for the data from each cat using an equation corresponding to drug disposition in a monocompartmental model with an absorption phase after dose normalization (equation 4):

$$
C_{\mathrm{e}}(t)=\frac{k_{e_{01}}}{V\left(k_{e 01}-k_{e 10}\right)}\left[e^{-k_{e 10} t}-e^{-k_{e 01} t}\right]
$$

where $V, k_{\mathrm{e} 01}$ and $k_{\mathrm{e} 10}$ are the volume of distribution (known volume of the tissue cage, between 6 and $10 \mathrm{~mL}$ ) and the firstorder absorption and elimination constants, respectively. No weighting was applied to the data for fitting. It was assumed that only a negligible amount of robenacoxib gained access to the tissue cage and that the drug kinetics in exudate had no effect on the time course of robenacoxib disposition in the rest of the body.

Standard PK parameters were generated by fitting equations (1-4) to the observed data and by noncompartmental analysis for individual cats, as follows:

a) maximum robenacoxib concentration, $C_{\max }$;

b) time of maximum robenacoxib concentration, $T_{\max }$;

c) area under robenacoxib concentration-time curve, $\mathrm{AUC}_{\text {last }}$ and $\mathrm{AUC}_{\text {inf; }}$;

d) area under the moment curve, $\mathrm{AUMC}_{\text {inf }}$;

e) robenacoxib mean residence time, mean residence time $(\mathrm{MRT})=\mathrm{AUMC}_{\mathrm{inf}} / \mathrm{AUC}_{\mathrm{inf}}$

f) slope of the elimination phase $\lambda_{\mathrm{z}}$, computed by linear regression of the logarithmic concentration vs. time curve during the elimination phase;

g) robenacoxib terminal half-life, $t_{1 / 2}=\ln (2) / \lambda_{\mathrm{z}}$;

h) robenacoxib clearance, $\mathrm{CL}=\operatorname{dose} / \mathrm{AUC}_{\mathrm{inf}}$;

i) volume of distribution of robenacoxib during the elimination phase, $V_{\text {area }} / F=($ dose $/ F) /\left(\mathrm{AUC}_{\text {inf }} \times \lambda_{\mathrm{z}}\right)$, where $F$ is the bioavailability for extravascular administration;

j) volume of distribution of robenacoxib at steady-state, $V_{\mathrm{ss}}=\mathrm{CL} \times \mathrm{MRT}$

\section{Exudate $\mathrm{PGE}_{2} \mathrm{PK} / \mathrm{PD}$ modelling (surrogate for COX-2 activity)}

A negative hysteresis precluded the use of a simple $I_{\max }$ PD model. The effect delay can be caused by a slow distribution of the drug to the site of action, by an indirect mechanism in generating the effect, by slow binding and release from a receptor or by the presence of an active metabolite (Ollerstam et al., 2006). The PK/PD relationship in exudate was best described by an indirect response model (Dayneka et al., 1993), in which the 
measured response $(R)$ varies according to factors that control either the input or the dissipation of the response (equation 5):

$$
\frac{\mathrm{d} R}{\mathrm{~d} t}=K_{\mathrm{in}}-K_{\mathrm{out}} R
$$

where $\mathrm{d} R / \mathrm{d} t$ is the rate of response $R$ change over time and $K_{\mathrm{in}}$, a zero-order rate constant for production of the response, and $K_{\text {out }}$, a first-order rate constant for dissipation of the response. In the case of the tissue cage, the measured response is the concentration of $\mathrm{PGE}_{2}$ in the tissue cage. The response is indirect because it is the consequence of a dynamic physiological equilibrium between processes that are inhibited or stimulated by the drug. Biological knowledge of the mechanism of action of NSAIDs on COX indicates that they reversibly compete with arachidonic acid for occupancy of the catalytic site and inhibit the build-up of $\mathrm{PGE}_{2}$ in the exudate (Josa et al., 2001) as in equation 6:

$$
\frac{\mathrm{dPGE}_{2}}{\mathrm{~d} t}=K_{\mathrm{in}}(t)-K_{\mathrm{out}} \mathrm{PGE}_{2}
$$

where $\mathrm{dPGE}_{2} / \mathrm{d} t(\mathrm{ng} / \mathrm{mL}$ per $\mathrm{h})$ is the rate of change of $\mathrm{PGE}_{2}$ concentration in exudate, $K_{\text {out }}(1 / \mathrm{h})$ is a first-order parameter expressing $\mathrm{PGE}_{2}$ disappearance rate, $K_{\text {in }}(t)(\mathrm{ng} / \mathrm{mL}$ per hour) is a zero-order time function expressing $\mathrm{PGE}_{2}$ production rate, and $K_{\text {in }}$ is considered as a time-dependant variable, influenced by carrageenan administration and robenacoxib concentration (in the period when administered). To express the action of carrageenan on $K_{\text {in }}$, a stimulation function (named stimulplacebo and stimulrobena) was selected as equations 7 and 8 for the placebo and robenacoxib periods, respectively:

$$
\begin{aligned}
& \text { stimulplacebo }=\operatorname{carrag} \times\left(e^{-k_{1} \times\left(t-t_{\operatorname{lag} 1}\right)}-e^{-k_{2} \times\left(t-t_{\operatorname{lag} 1}\right)}\right) \\
& \text { stimulrobena }=\operatorname{carrag} \times\left(e^{-k_{1} \times\left(t-t_{\operatorname{lag} 2}\right)}-e^{-k_{2} \times\left(t-t_{\operatorname{lag} 2}\right)}\right)
\end{aligned}
$$

where $k_{1}$ and $k_{2}$ are the first-order rate constants $(1 / \mathrm{h})$ describing the time development of the carrageenan stimulation, carrag is a scalar factor, and $t_{\operatorname{lag} 1}$ and $t_{\operatorname{lag} 2}$ represent the delay in the inflammation onset for the placebo and robenacoxib periods, respectively. Equations 7 and 8 assume that the effect of carrageenan stimulation of COX progressively builds up (as reflected by $k_{2}$ ) after injection and then steadily decreases (as reflected by $k_{1}$ ) (Lepist \& Jusko, 2004).

When robenacoxib was administered, it was assumed that it was able to mitigate the carrageenan action through an $I_{\max }$ function (Toutain \& Lees, 2004) of the form (equation 9):

$$
I(t)=1-\frac{I_{\max } \times C_{(t)}^{n}}{\mathrm{IC}_{50}^{n}+C_{(t)}^{n}}
$$

where $I(t)$ is a time-dependent scalar, $I_{\max }$ is a scalar fixed to 1 , expressing the fact that robenacoxib can totally inhibit carrageenan pro-inflammatory effect, $\mathrm{IC}_{50}$ is a parameter expressing the robenacoxib potency regarding the pro-inflammatory action of carrageenan, and $n$ is the Hill exponent expressing the steepness of the robenacoxib concentration vs. effect curve. Finally, incorporating equation 7 (for the placebo period) or equations 8 and 9 (for the robenacoxib period) in the general equation 6 , the time development of $\mathrm{PGE}_{2}$ concentration in exudate was described by equations 10 and 11 for the placebo and the robenacoxib period, respectively.

$$
\frac{\mathrm{dPGE}_{2}}{\mathrm{~d} t}=K_{\text {in }}(t)-K_{\text {out }} \mathrm{PGE}_{2}=K_{\text {in }} \times \text { stimuplacebo }-K_{\text {out }} \mathrm{PGE}_{2}
$$

$\frac{\mathrm{dPGE}_{2}}{\mathrm{~d} t}=K_{\text {in }} \times$ stimulrobena $\times\left[1-\frac{C(t)^{n}}{\mathrm{IC}_{50}^{n}+C(t)^{n}}\right]-K_{\text {out }} \mathrm{PGE}_{2}$

The equation of robenacoxib disposition in exudate was previously obtained by PK analysis (equation 4 ), and $C(t)$ was obtained by solving this equation with individual PK parameters that were entered as constants in the PK/PD model. The time course of exudate $\mathrm{PGE}_{2}$ for the placebo and the robenacoxib was modelled simultaneously, as the equations for both share several common parameters within the same cat $\left(K_{\text {in }}, K_{\text {out }}\right.$ and carrag, $k_{1}$ and $k_{2}$ ). Nine parameters were estimated by the model, namely $k_{\mathrm{in}}$, carrag, $k_{1}, k_{2}, t_{\mathrm{lag} 1}, t_{\mathrm{lag} 2}, k_{\text {out }}, \mathrm{IC}_{50}$ and $n$.

\section{Serum $T x B_{2} P K / P D$ modelling (surrogate for COX-1 activity)}

A sigmoid $I_{\max }$ model was selected to fit the serum $\mathrm{TxB}_{2}$ data. The equation of robenacoxib disposition in blood $C_{B}(t)$ was previously obtained by PK analysis (equations 1-3), and individual PK parameters were entered as constants to solve the PK/PD model. The robenacoxib concentration in the blood produced an inhibition of serum $\mathrm{TxB}_{2}$ synthesis according to the following sigmoid $I_{\max }$ model (equation 12):

$$
I\left(C_{B}\right)=I_{0}(t)-\frac{\left(I_{0}-I_{\max }\right) \times C_{B}^{n}}{\mathrm{IC}_{50}^{n}+C_{B}^{n}}
$$

where $I_{O}(t)$ represents the baseline serum $\mathrm{TxB}_{2}$ concentration $(\mathrm{ng} / \mathrm{mL})$ for a given cat, $I_{\max }(\%)$ is the percentage of maximal $\mathrm{TxB}_{2}$ suppression (corresponding to LLOQ of the assay) relative to $I_{0}(t), I_{50}(n g / m L)$ is the concentration that achieves half of the maximal $\mathrm{TxB}_{2}$ suppression, and $\mathrm{n}$ is the slope of the robenacoxib concentration-effect curve. In most cats, the serum $\mathrm{TxB}_{2}$ concentration had drifted below baseline by the end of the period when only the vehicle was administered. This drift of baseline throughout the course of the experiment was modelled as equation 13:

$$
I_{0}(t)=I_{0}-d \times t
$$

where $d$ represents the slope of the baseline function and $I_{0}$ the initial $\mathrm{TxB}_{2}$ concentration during the treatment period (Ollerstam et al., 2006). The slope was calculated by linear regression of the serum $\mathrm{TxB}_{2}$ concentration during the placebo period. Only data recorded during the first $24 \mathrm{~h}$ were used.

\section{Calculation of potency indices}

Individual concentration-effect curves were simulated using PD parameters expressing the maximal effect $\left(I_{\text {max }}\right)$, potency $\left(\mathrm{IC}_{50}\right)$ 
and steepness of the robenacoxib concentration-effect relationship (n) for ex vivo inhibition of COX-1 (15 cats) and in vivo inhibition of COX-2 (18 cats). A mean curve for COX-1 and COX-2 was fitted to the individual curves previously simulated ( 15 curves for COX-1 rescaled for $I_{\max }=100 \%$ and 18 curves for COX-2), using the same Hill equation (Giraudel et al., 2005b). The corresponding mean parameter values and 95\% confidence intervals were reported and used to calculate the selectivity indices, $\mathrm{IC}_{x} \mathrm{COX}-1 / \mathrm{IC}_{y} \mathrm{COX}-2$, to describe the in vivo selectivity. Finally, the predicted percentage of COX-1 inhibition was calculated for 50, 80, 95 and 99\% inhibition of COX-2.

Although the main source of $\mathrm{TxB}_{2}$ in serum is platelet COX-1, a minor contribution from COX-2 or from other cells cannot be completely excluded. Additionally, COX-1 may contribute to the synthesis of $\mathrm{PGE}_{2}$ in exudate (Nantel et al., 1999; Wallace et al., 1999), but the magnitude of this production is likely to be negligible based on the fact that COX-1 is not induced in carrageenan inflammatory models (Tomlinson et al., 1994).

\section{Statistics}

The results of the cross-over studies were analysed using a mixed effect model (SPSS version 17; SPSS Inc., Chicago, IL, USA) in which treatment, time, period and time $\mathrm{x}$ treatment interaction were fixed effects and cat was the random effect. The data were log-transformed to ensure normal distribution of residuals. The covariance structure was modelled as first-order autoregressive to account for the fact that adjacent observations are likely to be more correlated than more distant observations in repeated measures design (Littell et al., 1998; Kristensen \& Hansen, 2004). Figures and potency curve fitting were computed using Prism version 4.03 (GraphPad, La Jolla, CA, USA). All reported $P$ values are two-tailed, with statistical significance defined as $P \leq 0.05$. In the post hoc tests, multiple analyses were corrected for using the Bonferroni method.

\section{RESULTS}

\section{Analytical method quality control}

For the HPLC-UV and LC-MS blood robenacoxib measurement methods, interassay inaccuracy was $<6.7 \%$ and $10.4 \%$, respectively, and interassay imprecision was $<7 \%$ and $9.3 \%$, respectively. For the LC-MS exudate robenacoxib method, interassay inaccuracy was $<8.5 \%$ and interassay imprecision was $<7.7 \%$.

Exudate $\mathrm{PGE}_{2}$ intra-assay variability was $3 \%$ for the high control concentration $(2.9 \mathrm{ng} / \mathrm{mL})$ and $23.9 \%$ for the low control concentration $(0.13 \mathrm{ng} / \mathrm{mL})$. Interassay variability was $2.1 \%$ for the high control and $31 \%$ for the low control concentrations.

Serum $\mathrm{TxB}_{2}$ intra-assay variability was $7.2 \%$ for the high control $(235.1 \mathrm{ng} / \mathrm{mL})$ and $13.2 \%$ for the low control concentrations $(56.5 \mathrm{ng} / \mathrm{mL})$. Interassay variability was $2.3 \%$ and $11.3 \%$ for the high and low control concentrations, respectively.

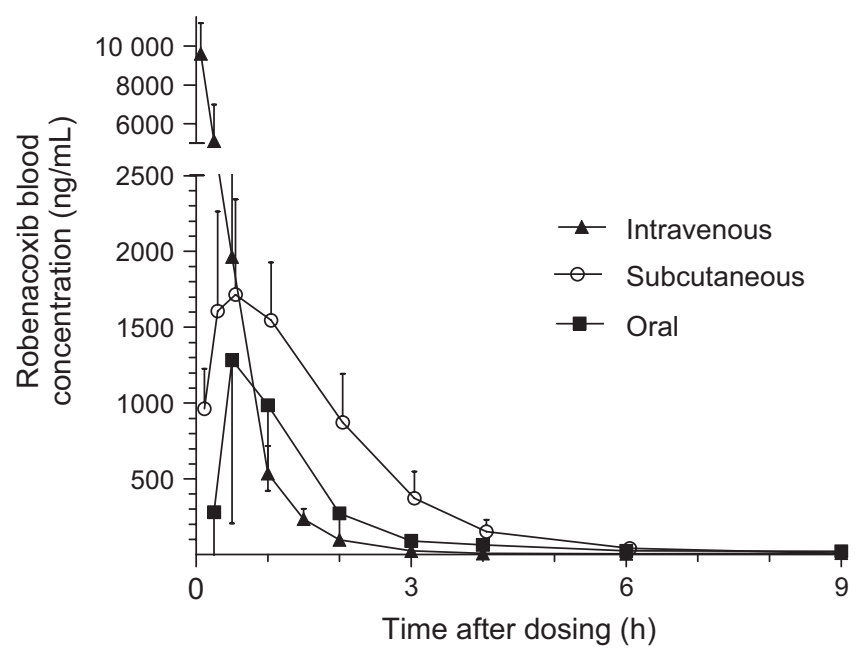

Fig. 1. Observed (mean $\pm \mathrm{SD})$ blood robenacoxib concentration $(\mathrm{ng} / \mathrm{mL})$ vs. time (h) profile after single robenacoxib administration by intravenous (nominal dose of $2 \mathrm{mg} / \mathrm{kg}$ in eight cats), subcutaneous (nominal dose of $2 \mathrm{mg} / \mathrm{kg}$ in eight cats) or oral (6 mg dose in seven cats) route.

All validation data complied with analytical recommendations guidelines (Kelley \& DeSilva, 2007; Viswanathan et al., 2007) except for $\mathrm{PGE}_{2}$ interassay variability. As a consequence, all samples of the same cats were always analysed in the same batch.

\section{Pharmacokinetics of robenacoxib}

Both the blood and exudate sampling protocols used in this study were well tolerated and exudate samples were obtained on every intended occasion in all cats. Blood robenacoxib concentration-time profiles after intravenous, subcutaneous and oral administration are represented in Fig. 1. Table 1 summarizes PK parameters for the three routes of administration.

Robenacoxib disposition after intravenous administration was well described by a two-compartment model. Extrapolated maximal concentration at time 0 was $9091 \mathrm{ng} / \mathrm{mL}$ (95\% CI: 7919-10436), blood clearance was $0.54 \mathrm{~L} \cdot \mathrm{h} / \mathrm{kg}$ (95\% CI: $0.47-$ $0.58)$, and MRT was $0.36 \pm 0.042 \mathrm{~h}$. All cats had detectable robenacoxib blood concentrations at $9 \mathrm{~h}$. Two cats had higher concentrations at $9 \mathrm{~h}$ than at $6 \mathrm{~h}$.

Blood robenacoxib disposition after subcutaneous injection was described by a bicompartmental model with a rapid absorption phase. Peak blood concentration was $1905 \mathrm{ng} / \mathrm{mL}$ (95\% CI: 1604-2284) and was reached $0.60 \mathrm{~h}$ after injection. Apparent clearance $(\mathrm{CL} / F$, i.e. clearance scaled by bioavailability) was $0.54 \mathrm{~L} \cdot \mathrm{h} / \mathrm{kg}$ (95\% CI: 0.46-0.60), and MRT was $1.9 \pm 0.41 \mathrm{~h}$.

The administered oral dose ranged from 1.25 to $1.6 \mathrm{mg} / \mathrm{kg}$ as only entire robenacoxib tablets were administered. Because of malfunction of two catheters during one sampling period, the PK profile was truncated at $120 \mathrm{~min}$ for one cat and at $240 \mathrm{~min}$ for the other. Apparent clearance $(\mathrm{CL} / F)$ was $0.71 \mathrm{~L} \cdot \mathrm{kg} / \mathrm{h}(95 \% \mathrm{CI}$ : 0.63-0.86), and MRT was $3.3 \pm 4.05 \mathrm{~h}$. Mean $C_{\max }(794 \mathrm{ng} /$ $\mathrm{mL}, 95 \%$ CI: $242-2011$ ) was reached after $1.64 \pm 2.5 \mathrm{~h}$. Two 


\begin{tabular}{|c|c|c|c|}
\hline & $\begin{array}{c}\text { Intravenous } \\
\quad(n=7)\end{array}$ & $\begin{array}{l}\text { Subcutaneous } \\
\quad(n=8)\end{array}$ & $\begin{array}{c}\text { Oral } \\
(n=6)\end{array}$ \\
\hline Dose (mg/kg) & 2 & 2 & $1.49(0.13)$ \\
\hline$T_{\max }(\mathrm{h})$ & $\mathrm{NC}$ & $0.60(0.222)$ & $1.64(2.51)$ \\
\hline$C_{0}$ or $C_{\max }(\mathrm{ng} / \mathrm{mL})$ & 9091 (7919-10436) & 1905 (1604-2284) & $794(242-2011)$ \\
\hline $\mathrm{AUC}_{\text {last }}($ dose norm $)(\mathrm{ng} \cdot \mathrm{h} / \mathrm{L})$ & $1864(1727-2148)$ & $1861(1668-2178)$ & 958 (827-987) \\
\hline $\mathrm{AUC}_{\text {inf }}($ dose norm $)(\mathrm{ng} \cdot \mathrm{h} / \mathrm{L})$ & $1866(1730-2159)$ & $1867(1673-2186)$ & $1055(773-1320)$ \\
\hline MRT (h) & $0.361(0.049)$ & $1.68(0.408)$ & $3.32(4.047)$ \\
\hline Elimination $t_{1 / 2}(\mathrm{~h})$ & $0.843(0.280)$ & $1.04(0.348)$ & $0.78(0.544)$ \\
\hline CL or CL_F (L/kg/h) & $0.54(0.47-0.58)$ & $0.54(0.46-0.60)$ & $0.71(0.63-0.86)$ \\
\hline Vd or Vd_F $(\mathrm{L} / \mathrm{kg})$ & $0.69(0.48-1.03)$ & $0.84(0.65-1.03)$ & $1.13(0.60-3.65)$ \\
\hline$V_{\mathrm{ss}}(\mathrm{L} / \mathrm{kg})$ & $0.19(0.16-0.23)$ & $\mathrm{NC}$ & $\mathrm{NC}$ \\
\hline
\end{tabular}

Table 1. Blood parameters obtained by PK analysis after single intravenous $(2 \mathrm{mg} / \mathrm{kg}$, in seven cats), subcutaneous $(2 \mathrm{mg} / \mathrm{kg}$, in eight cats) or oral (6 mg tablet in seven cats) administration of robenacoxib

AUC, area under the blood concentration-time curve; (dose norm), AUCs were normalised by individual doses to a dosage regimen of $\mathrm{l} \mathrm{mg} / \mathrm{kg}$; MRT, mean residence time; CL or CL_F, blood clearance or apparent clearance; $V$ or $V_{-} \mathrm{F}$, volume of the central compartement; $V_{\mathrm{ss}}$, volume of distribution at steady state.

$T_{\max }$ and MRT are presented as arithmetic mean (SD). All other parameters are presented as geometric mean (95\% Confidence Interval). Half-lives are presented as harmonic mean with SD estimated by the Jack Knife method. Calculation methods of the following parameters and variables are given in the text. $T_{\max }$ (time of peak blood concentration) and $C_{\max }$ (peak blood concentration) were calculated with a compartmental method. $\mathcal{C}_{0}$ is the extrapolated concentration at time 0 for intravenous dosing, $C_{0}$ and $C_{\max }$ are not dose-normalised.

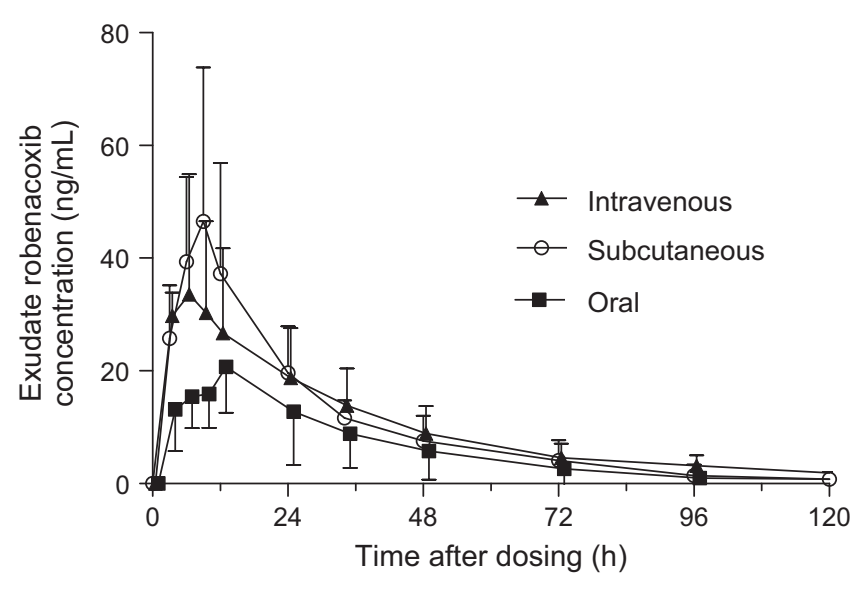

Fig. 2. Observed (mean $\pm \mathrm{SD}$ ) exudate robenacoxib concentration (ng/mL) vs. time (h) profile after single robenacoxib administration by intravenous (nominal dose of $2 \mathrm{mg} / \mathrm{kg}$ in eight cats), subcutaneous (nominal dose of $2 \mathrm{mg} / \mathrm{kg}$ in nine cats) and oral (6 $\mathrm{mg}$ dose in seven cats) route.

outliers had a prolonged absorption phase and a lower $C_{\max }$ than the other cats.

The PK of robenacoxib in the tissue cage followed a monocompartmental disposition with a rapid absorption phase and slow release (Fig. 2), regardless of the route of administration. Exudate PK parameters and variables are reported in Table 2. The maximal exudate concentration after intravenous administration (31.5 ng/mL, 95\% CI: 21.7-48.4) was reached after $4.4 \pm 2.6 \mathrm{~h}\left(T_{\max }\right)$, with a mean absorption half-life $K_{\mathrm{e} 01}$ of $0.5 \mathrm{~h}$. Time to reach maximal exudate concentration was longer after subcutaneous $\left(T_{\max } 7.1 \pm 1.8 \mathrm{~h}\right.$ and $\left.t_{1 / 2} K_{\mathrm{e} 01} 2.0 \pm 1.1 \mathrm{~h}\right)$ and oral $\left(T_{\max } 9.6 \pm 6.5 \mathrm{~h}\right.$ and $\left.t_{1 / 2} K_{\mathrm{e} 01} 1.9 \pm 1.7 \mathrm{~h}\right)$ administrations. $C_{\max }$ after subcutaneous administration (39.9 $\mathrm{ng} / \mathrm{mL}$, 95\% CI: 30.5-68.7) was higher than that after intravenous, in contrast to $C_{\max }$ after oral administration which was lower (17.9 ng/mL, 95\% CI: 17.2-25.3). Although exudate elimination half-life $t_{1 / 2} K_{\mathrm{e} 10}$ was longer after intravenous administration $(21.7 \pm 7.3 \mathrm{~h})$ in comparison with subcutaneous $(12.2 \pm 5.5 \mathrm{~h})$ and oral $(16.6 \pm 9.8 \mathrm{~h})$ administration, MRT values were similar for the three routes of administration (25.9, 23.3 and 23.5 h, respectively).

\section{Pharmacodynamics of robenacoxib}

Exudate $\mathrm{PGE}_{2}$ concentration-time course is represented in Fig. 3a for intravenous administration and in Fig. 3b. for subcutaneous/oral administration. Peak $\mathrm{PGE}_{2}$ concentrations after placebo administration were attained at $24 \mathrm{~h}$. The increase in $\mathrm{PGE}_{2}$ generation after robenacoxib administration in the exudate was significantly different from placebo between 6 and $24 \mathrm{~h}$ after intravenous administration $(P<0.05$, mixed effect model $)$. There was a significant decrease in exudate $\mathrm{PGE}_{2}$ at $12 \mathrm{~h}$ after oral administration. After intravenous administration, maximum exudate $\mathrm{PGE}_{2}$ inhibition was $88.9 \%$ at $6 \mathrm{~h}$, when exudate robenacoxib concentration was $35.4 \pm 24.9 \mathrm{ng} / \mathrm{mL}$. Maximum exudate $\mathrm{PGE}_{2}$ inhibition was $86.6 \%$ at $9 \mathrm{~h}$ after subcutaneous administration (exudate robenacoxib concentration 31.8 $\pm 21.3 \mathrm{ng} / \mathrm{mL}$ ) and $90.0 \%$ at $6 \mathrm{~h}$ after oral administration (exudate robenacoxib concentration $15.5 \pm 5.6 \mathrm{ng} / \mathrm{mL}$ ).

Serum $\mathrm{TxB}_{2}$ concentration-time course for intravenous administration is presented in Fig. 4a. Owing to technical problems related to catheters implantation or patency, there were missing points or whole periods in the serum $\mathrm{TxB}_{2}$ dataset (two periods for placebo, one period for subcutaneous and two incomplete curves for oral administration). There was no 
Table 2. Exudate PK parameters and variables obtained by PK analysis after single intravenous $(2 \mathrm{mg} / \mathrm{kg})$, subcutaneous $(2 \mathrm{mg} / \mathrm{mg})$ or oral $(6 \mathrm{mg}$ tablet $)$ administration of robenacoxib
PK exudate parameters and variables for robenacoxib after intravenous, subcutaneous or oral administration

\begin{tabular}{lccc}
\hline & $\begin{array}{c}\text { Intravenous } \\
(n=8)\end{array}$ & $\begin{array}{c}\text { Subcutaneous } \\
(n=9)\end{array}$ & $\begin{array}{c}\text { Oral } \\
(n=8)\end{array}$ \\
\hline Dose $(\mathrm{mg} / \mathrm{kg})$ & 2.0 & 2.0 & $1.49(0.13)$ \\
$T_{\max }(\mathrm{h})$ & $4.4(2.55)$ & $7.1(1.79)$ & $9.6(6.54)$ \\
$C_{\max }(\mathrm{ng} / \mathrm{mL})$ & $31.5(21.7-48.4)$ & $39.9(30.5-68.7)$ & $17.9(17.2-25.3)$ \\
$K_{\mathrm{e} 01}(1 / \mathrm{h})$ & $0.92(0.46-1.63)$ & $0.3(0.23-0.53)$ & $0.26(0.10-0.57)$ \\
$K_{\mathrm{el0}}(1 / \mathrm{h})$ & $0.03(0.02-0.04)$ & $0.06(0.04-0.07)$ & $0.04(0.02-0.06)$ \\
$t_{1 / 2} K_{\mathrm{e} 01}(\mathrm{~h})$ & $0.5(0.47)$ & $2.0(1.13)$ & $1.9(1.66)$ \\
$t_{1 / 2} K_{\mathrm{elo}}(\mathrm{h})$ & $21.7(7.33)$ & $12.2(5.72)$ & $16.2(9.82)$ \\
$\mathrm{MRT}(\mathrm{h})$ & $25.9(6.72)$ & $23.3(4.94)$ & $23.5(11.29)$ \\
$\mathrm{AUC}(\mathrm{ng} \cdot \mathrm{h} / \mathrm{mL})$ & $1123(848-1603)$ & $1235(881-1535)$ & $720(447-1160)$ \\
\hline
\end{tabular}

$T_{\max }$, time to reach peak exudate concentration; $C_{\max }$, peak exudate concentration; $K_{\mathrm{eOl}}$ and $K_{\mathrm{el} 0}$,

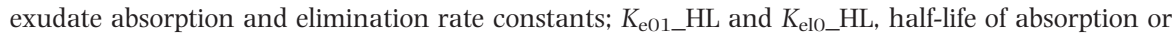
elimination; AUC, area under the exudate concentration time curve; MRT, mean residence time calculated with non-compartmental analysis.

$T_{\max }$ and MRT are presented as arithmetic mean (SD). All other parameters are presented as geometric mean $(95 \%$ Confidence Interval). Half-lives are presented as harmonic mean with SD estimated by the Jack Knife method. PK parameters were dose-normalised for a unitary dose. significant difference $(P=0.09)$ between groups in the initial serum $\mathrm{TxB}_{2}$ concentrations, with $112.9 \pm 40.9 \mathrm{ng} / \mathrm{mL}$ for robenacoxib and $104.5 \pm 73.7 \mathrm{ng} / \mathrm{mL}$ for placebo. Maximum measured serum $\mathrm{TxB}_{2}$ inhibition was $83 \%$ at $5 \mathrm{~min}$, when blood robenacoxib concentration was $9606 \pm 1580 \mathrm{ng} / \mathrm{mL}$. Serum $\mathrm{TxB}_{2}$ after intravenous robenacoxib was significantly lower than placebo at 5, $15(P<0.001)$ and $30 \mathrm{~min}(P<0.05)$.

The serum $\mathrm{TxB}_{2}$ concentration-time profile after subcutaneous and oral administration is presented in Fig. $4 \mathrm{~b}$. The baseline $\mathrm{TxB}_{2}$ concentration for oral robenacoxib was lower than in the two other groups $(144 \pm 43.7$ vs. $198 \pm 65.3 \mathrm{ng} / \mathrm{mL}$ for placebo and $189 \pm 49.6 \mathrm{ng} / \mathrm{mL}$ for subcutaneous) but the difference was not significant $(P=0.32$ vs. placebo and $P=0.52$ vs. subcutaneous treatment). There was no significant effect of robenacoxib at any time point. Serum $\mathrm{TxB}_{2}$ inhibition was at most weak after oral (maximal inhibition $32.5 \%$ at $2 \mathrm{~h}$ ) or subcutaneous (maximal inhibition $27.6 \%$ at $0.5 \mathrm{~h}$ ) administration in comparison with the inhibition after intravenous administration.

\section{PK/PD modelling}

Exudate $\mathrm{PGE}_{2} \mathrm{PK} / \mathrm{PD}$ modelling. The model gave excellent results in 18 out 24 attempts, when raw data for all experimental periods were consistent. Modelling was unsuccessful or led to unrealistic estimations of PD parameters in two cases, because tissue cages produced more $\mathrm{PGE}_{2}$ with robenacoxib than with placebo, accounting for three failures. In two cases, the amount of $\mathrm{PGE}_{2}$ produced when placebo was administered was very low. In the last case, robenacoxib $\mathrm{PGE}_{2}$ inhibition never decreased below $50 \%$ over the $120 \mathrm{~h}$ sampling period.

An example of an indirect response model simultaneously fitted to observed values with placebo (equation 10) and intravenous robenacoxib administration (equation 11) is illustrated in Fig. 5b. Estimates of the PD model parameters for $\mathrm{PGE}_{2}$ after intravenous, subcutaneous or oral administration are presented in Table 3. Overall $t_{\text {lags }}$ after carrageenan injection were $9 \pm 8.8 \mathrm{~h}$ for placebo and $11.1 \pm 9.5 \mathrm{~h}$ for robenacoxib. Estimates of PD parameters for the surrogates of COX-1 and COX-2 activity are presented in Table 5 and Fig. 6. For COX-2, the PD estimate for $\mathrm{IC}_{50}$ was $14.1 \mathrm{ng} / \mathrm{mL}$ (95\% CI: $12.5-$ $16.0 \mathrm{ng} / \mathrm{mL}$ ) and the estimate for the slope $n$ was 1.12 (95\% CI: 0.98-1.25). $I_{\max }$ was set as 1 in the indirect response model.

Serum $T x B_{2}$ PK/PD modelling. The PK/PD modelling for COX-1 was carried out with the intravenous and subcutaneous dataset only (15 datasets in total), as inhibitory effect of blood robenacoxib concentrations after oral administration was too small to allow reliable modelling for this isoform. An example of PK/PD $I_{\max }$ model fitting is represented in Fig. 5a. The PD parameters are reported in Table 4. Both intravenous and subcutaneous datasets were fitted using the sigmoid $I_{\text {max }}$ model. The intravenous dataset required weighting the data by the reciprocal of the predicted value. When the two datasets were combined, $I_{\max }$ was $96.6 \pm 1.3 \%$, which required re-scaling of the potency curves to a maximal effect of $100 \%$. For COX-1, the $\mathrm{PD}$ estimate for $\mathrm{IC}_{50}$ was $2416 \mathrm{ng} / \mathrm{mL}$ (95\% CI: 2245$2600 \mathrm{ng} / \mathrm{mL})$ and the estimate for the slope $n$ was $1.36(95 \%$ CI: 1.23-1.48) (Table 5).

Selectivity indices. Table 6 presents three categories of indices to describe the in vivo/ex vivo selectivity of robenacoxib. In addition, the data from Giraudel et al. (2009b), obtained using a nonlinear mixed effect model and based on whole-blood in vitro assays, are included for comparison. The $\mathrm{IC}_{50} \mathrm{COX}-1 / \mathrm{IC}_{50} \mathrm{COX}-$ 2 ratio was 171:1 for the present data, using the naïve pooled approach. The selectivity was high at nearly maximal inhibition, as $\mathrm{IC}_{99} \mathrm{COX}-1 / \mathrm{IC}_{99} \mathrm{COX}-2$ was 82.5:1. Other composite indices, useful for the evaluation of clinical efficacy and safety, were computed. The clinically relevant $\mathrm{IC}_{20} \mathrm{COX}-1 / \mathrm{IC}_{80} \mathrm{COX}-2$ ratio was $17.8: 1$. Finally, the percentage inhibition of COX-1 was 

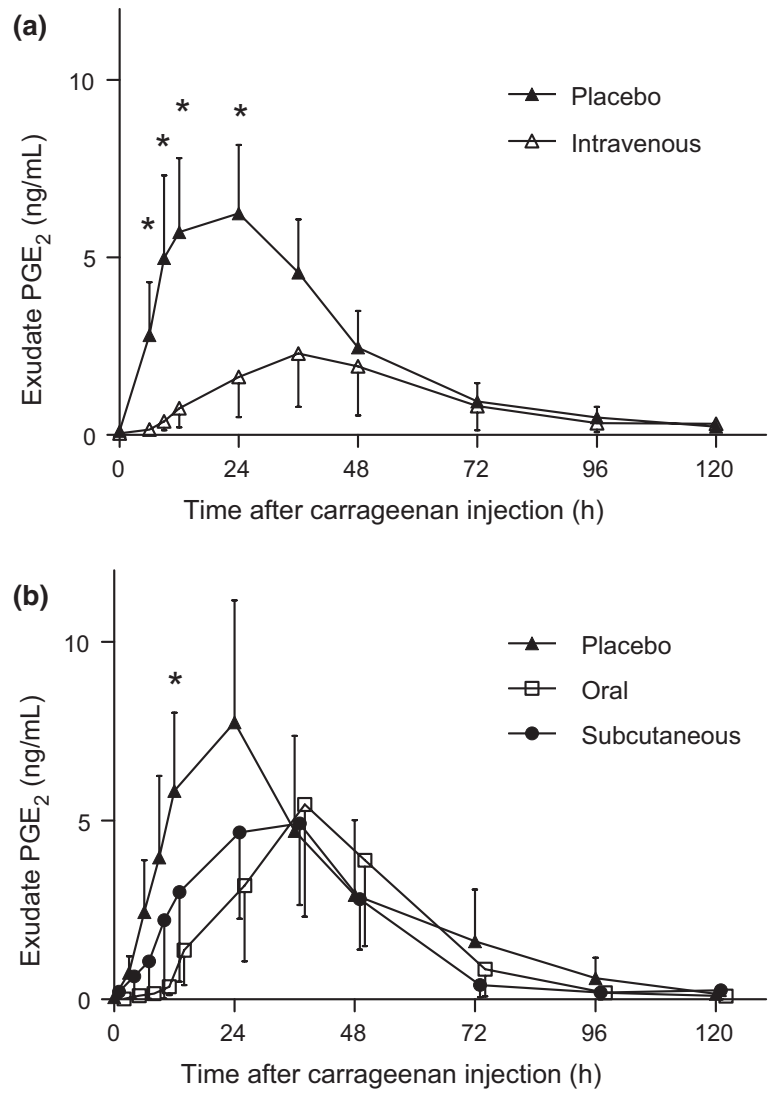

Fig. 3 Mean $( \pm S E M)$ exudate $\mathrm{PGE}_{2}$ concentration $(\mathrm{ng} / \mathrm{mL})$ vs. time $(\mathrm{h})$ after carrageenan injection profile. SEM was plotted instead of SD as PK-PD modelling is relevant to the response as a whole rather to the response at sampling time taken separately. (a) Intravenous and placebo administration (eight cats). One cat which did not respond to carrageenan was excluded. A significant difference was obtained at 6, 9, 12 and $24 \mathrm{~h}$ $\left({ }^{*} P<0.05\right.$, Bonferroni correction, mixed effect model). (b) Subcutaneous (eight cats), oral (six cats) and placebo administration. One cat which did not respond to carrageenan was excluded. Significant effect of oral treatment compared to placebo at $12 \mathrm{~h}\left({ }^{*} \mathrm{P}<0.05\right.$, Bonferroni correction, mixed effect model).

calculated for a given percentage in the inhibition of COX-2. There was virtually no inhibition of COX-1 for 50\% inhibition of COX-2, 1.4\% inhibition of COX-1 for 95\% COX-2 inhibition and $19.8 \%$ inhibition of COX-1 for $99 \%$ inhibition of COX-2.

\section{DISCUSSION}

The tissue cage model enables the study of an acute inflammatory response in a humane manner as well as repeated collection of exudate samples in a sufficient volume to quantify exudate drug concentrations and inflammatory mediators (such as $\mathrm{PGE}_{2}$ ) up to $120 \mathrm{~h}$ after carrageenan injection (Pelligand et al., 2011).

The principal findings of the present study are that robenacoxib had a markedly longer residence time in tissue cage exudate compared to blood in cats, and this finding correlated with longlasted inhibition of exudate $\mathrm{PGE}_{2}$. In addition, the results confirm the high selectivity of robenacoxib for COX-2 compared to COX-1
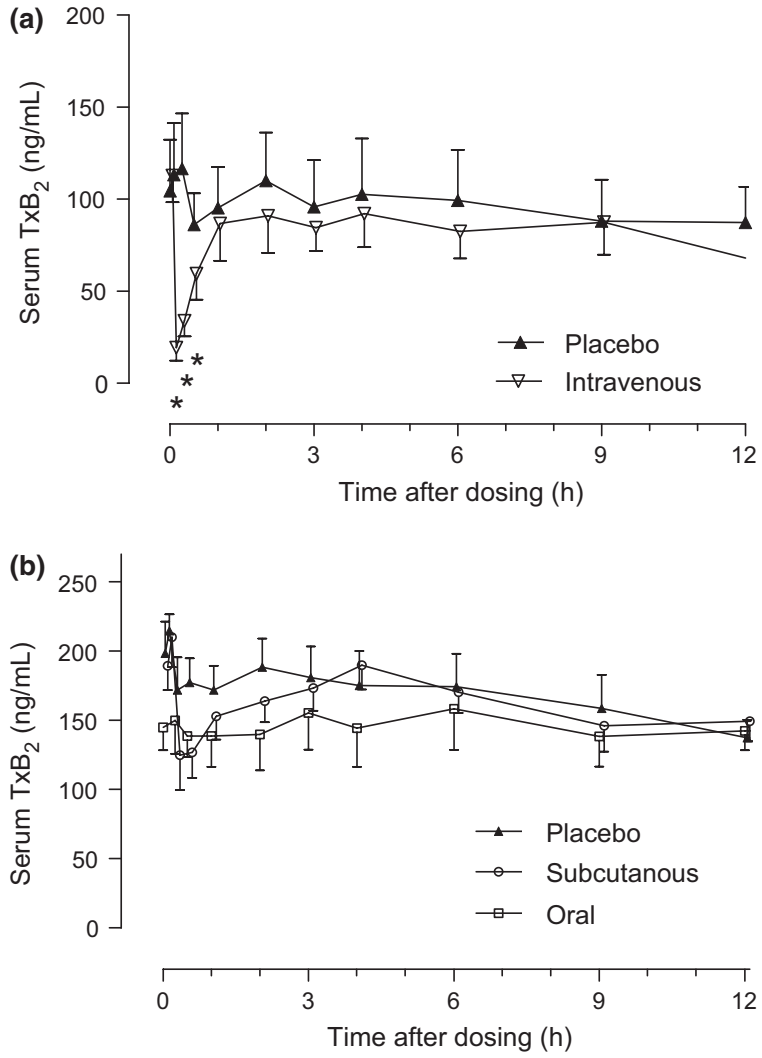

Fig. 4. Mean ( \pm SEM) serum $\mathrm{TxB}_{2}$ concentration (ng/mL) vs. time (h) profile after robenacoxib dosing. SEM was plotted instead of SD as PK-PD modelling is relevant to the response as a whole rather to the response at sampling time taken separately. (a) Intravenous and placebo (eight cats) administration. A significant difference was obtained at 5, 15 and $30 \mathrm{~min}\left({ }^{*} \mathrm{P}<0.05\right.$, Bonferroni correction, mixed effect model). (b) Subcutaneous (eight cats), oral (six cats) and placebo administration. No significant difference after pair-wise comparison.

in the cat, as noted in previous studies (Giraudel et al., 2009b; Schmid et al., 2010).

\section{Robenacoxib PK in the tissue cage model}

Dependency of exudate PK upon blood PK. The concentration-time profiles indicated that the highest robenacoxib blood concentration was achieved after intravenous, then subcutaneous and finally oral administration. For both extravascular routes, absorption was rapid as $T_{\max }$ occurred after $0.56 \mathrm{~h}$ (subcutaneous) to $0.93 \mathrm{~h}$ (oral). The dose-normalized AUC was similar for intravenous and subcutaneous routes, and lower for oral administration, reflecting mainly the differences in bioavailability as described (J.N. King, M. Jung, M.P. Maurer, W. Seewald, V. Schmid \& P. Lees, unpublished data). Blood clearance after intravenous administration was rapid $(0.54 \mathrm{~L} \cdot \mathrm{kg} / \mathrm{h}$ or approximately $9 \mathrm{~mL} \cdot \mathrm{kg} / \mathrm{min}$ ), which was slightly higher than previously found in the cat $(0.44 \mathrm{~L} \cdot \mathrm{kg} / \mathrm{h})$ (J.N. King, M. Jung, M.P. Maurer, W. Seewald, V. Schmid \& P. Lees, unpublished data). Terminal half-lives after intravenous, subcutaneous or oral 
Fig. 5. Observed and fitted serum $\mathrm{TxB}_{2}$ $(\mathrm{ng} / \mathrm{mL})$ and exudate $\mathrm{PGE}_{2}(\mathrm{ng} / \mathrm{mL})$ vs. time (h) profiles after carrageenan injection and robenacoxib dosing. Serum $\mathrm{TxB}_{2}$ and exudate $\mathrm{PGE}_{2}$ time courses act as surrogate markers for COX-1 and COX-2 activities, respectively. (a) Example of serum $\mathrm{TxB}_{2}$ time course after intravenous, robenacoxib and placebo administration (time 0). The data were fitted with an $I_{\max }$ model including a drift of baseline to account for the slow decline of $\mathrm{TxB}_{2}$ along the sampling interval, as detailed in equation 13. (b) Example of exudate $\mathrm{PGE}_{2}$ time course after carrageenan injection and intravenous robenacoxib and placebo administration (time 0). An indirect response model including the time course of carrageenan inflammation for both periods was fitted to the data (see Materials and methods).
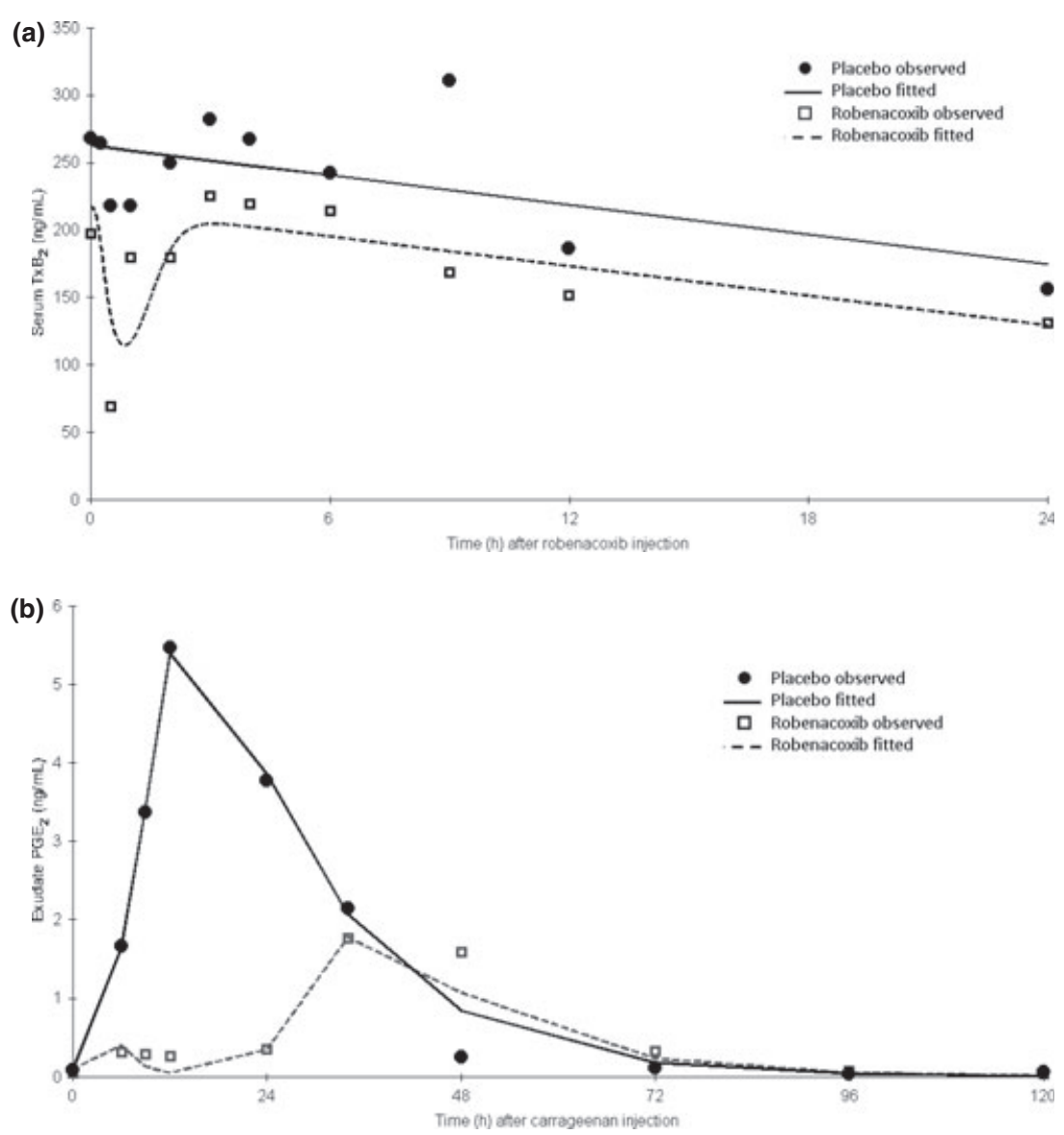

administration were between 0.6 and $1.04 \mathrm{~h}$ (harmonic means), which were slightly shorter than reported half-life harmonic means between 0.97 and $1.7 \mathrm{~h}$ previously calculated for robenacoxib in cats (J.N. King, M. Jung, M.P. Maurer, W. Seewald, V. Schmid \& P. Lees, unpublished data; Schmid et al., 2010). However, similarity of the terminal half-lives for the three administration routes in this study suggests that flip-flop PK did not occur. In two cats, there was a protracted or biphasic absorption pattern after oral administration. Interanimal variability in the oral absorption profile was also described previously, leading to delayed $C_{\max }$ and reduced bioavailability in some cats (J.N. King, M. Jung, M.P. Maurer, W. Seewald, V. Schmid \& P. Lees, unpublished data). This was probably related to food intake, as it occurred more often in fed than in fasted animals, and therefore, robenacoxib tablets are recommended to be administered either without or with a small quantity of food.

The delay in exudate $T_{\max }$ after subcutaneous and oral when compared with intravenous dosing is consistent with systemic absorption with the nonvascular administration routes. In exudate, $C_{\max }$ and AUC were slightly higher after subcutaneous than after intravenous administration, whereas oral administration (mean dose $=1.49 \pm 0.13 \mathrm{mg} / \mathrm{kg}$ ) produced lower $C_{\max }$ and AUC values. Exudate robenacoxib AUC and $C_{\max }$ were correlated with robenacoxib AUC in blood rather than blood robenacoxib $C_{\max }$. Thus, the concentration gradient between blood and exudate and, more importantly, the time during which the gradient is maintained, together determine the extent of robenacoxib penetration into exudate. The higher exudate $C_{\max }$ obtained with subcutaneous compared with intravenous administration is due to the longer persistence of the blood robenacoxib concentration with subcutaneous administration. Despite rapid clearance from blood, robenacoxib concentrations were well maintained at the site of inflammation, as MRT was close to $24 \mathrm{~h}$ for all the routes of administration.

Long residence time: hypothesis. One hypothesis for the marked difference in residence time between blood and exudate is the limitation of passive diffusion (Fick's law) of robenacoxib out of the cage by the small surface area of exchange imposed by the geometry of the tissue cage. Exudate and plasma creatinine clearances were estimated previously (Pelligand et al., 2011) after intravenous bolus injection of creatinine $(40 \mathrm{mg} / \mathrm{kg})$ in eight cats. Creatinine is a low molecular weight solute for which equilibration between plasma and exudate follows Fick's law of diffusion (involving exchange surface area, thickness and permeability). Creatinine was cleared rapidly from plasma by renal filtration $\left(\mathrm{MRT}_{\text {plasma }}\right.$ for creatinine were $3.1 \pm 0.89 \mathrm{~h}$ ) but persisted for longer in the exudate ( $\mathrm{MRT}_{\text {exudate }} 11.2 \pm 2.29 \mathrm{~h}$ ), giving a creatinine $\mathrm{MRT}_{\text {exudate }} / \mathrm{MRT}_{\text {plasma }}$ ratio of $3.6: 1$. In comparison, robenacoxib $\mathrm{MRT}_{\text {exudate }} / \mathrm{MRT}_{\text {blood }}$ ratio was 56.3:1, 14.3:1 and 15.3:1 after intravenous, subcutaneous and oral 


\begin{tabular}{|c|c|c|c|}
\hline $\begin{array}{l}\text { Number of suc- } \\
\text { cessful modellings }\end{array}$ & $\begin{array}{l}\text { Intravenous route } \\
n^{*}=5 \text { out of } 8\end{array}$ & $\begin{array}{l}\text { Subcutaneous route } \\
n^{*}=7 \text { out of } 9\end{array}$ & $\begin{array}{c}\text { Oral route } \\
n^{*}=6 \text { out of } 7\end{array}$ \\
\hline Parameters & Mean (SD) & Mean (SD) & Mean (SD) \\
\hline$K_{\text {in }}(\mathrm{ng} \cdot \mathrm{mL} / \mathrm{h})$ & $0.33(0.15)$ & $0.14(0.10)$ & $0.62(0.57)$ \\
\hline Carrag (no unit) & $37.7(25.4)$ & $75.2(19.2)$ & $72.0(30.7)$ \\
\hline$K_{\mathrm{l}}(\mathrm{l} / \mathrm{h})$ & $0.6(0.90)$ & $0.63(0.67)$ & $0.31(0.25)$ \\
\hline$K_{2}(\mathrm{l} / \mathrm{h})$ & $0.08(0.07)$ & $0.13(0.05)$ & $0.07(0.03)$ \\
\hline$n$ (no unit) & $3.26(0.77-14.0)$ & $2.02(0.85-4.76)$ & $2.5(0.74-8.74)$ \\
\hline $\begin{array}{l}\mathrm{EC}_{50} \mathrm{COX}-2 \\
(\mathrm{ng} / \mathrm{mL})\end{array}$ & $4.6(0.4-52.8)$ & $20.0(5.1-78.4)$ & $14.1(4.28-46.68)$ \\
\hline$K_{\text {out }}(\mathrm{l} / \mathrm{h})$ & $0.42(0.51)$ & $0.27(0.36)$ & $1.01(0.72)$ \\
\hline$T_{\text {lagl }}(\mathrm{h})$ & $4.87(2.58)$ & $9.2(9.3)$ & $11.6(11.3)$ \\
\hline$T_{\text {lag2 }}(\mathrm{h})$ & $6.97(10.52)$ & $15.1(10.3)$ & $9.8(7.00)$ \\
\hline
\end{tabular}

*Due to unsatisfactory model fitting: inverse dose effect relationship or no placebo stimulation (reasons in text), excluded from the mean calculation. All parameters are expressed as arithmetic means (SD) except $n$ and $\mathrm{EC}_{50}$ (geometric mean and [95\% Confidence Interval]). $K_{1}$ and $K_{2}$, first order time-dependant variable for growth and dissipation of carrageenan stimulation on COX (respectively); Carrag is a scalar; $K_{\mathrm{in}}$, zero-order constant for basal $\mathrm{PGE}_{2}$ production; $K_{\text {out }}$, first-order rate constant for removal of $\mathrm{PGE}_{2}$ from exudate; $T_{\text {lagl }}$ and $T_{\text {lag2 }}$, lag time between injection of carrageenan and beginning of the carrageenan stimulation.
Table 3. Estimated PD parameters (mean and SD) describing the inhibitory effect of robenacoxib on exudate $\mathrm{PGE}_{2}$ production after intravenous (eight cats, nominal dose of $2 \mathrm{mg} / \mathrm{kg}$ ), subcutaneous (nine cats, nominal dose of $2 \mathrm{mg} / \mathrm{kg}$ ) and oral administration (seven cats, dose $6 \mathrm{mg} / \mathrm{cat}$ ). An indirect response model including nine estimated parameters was computed

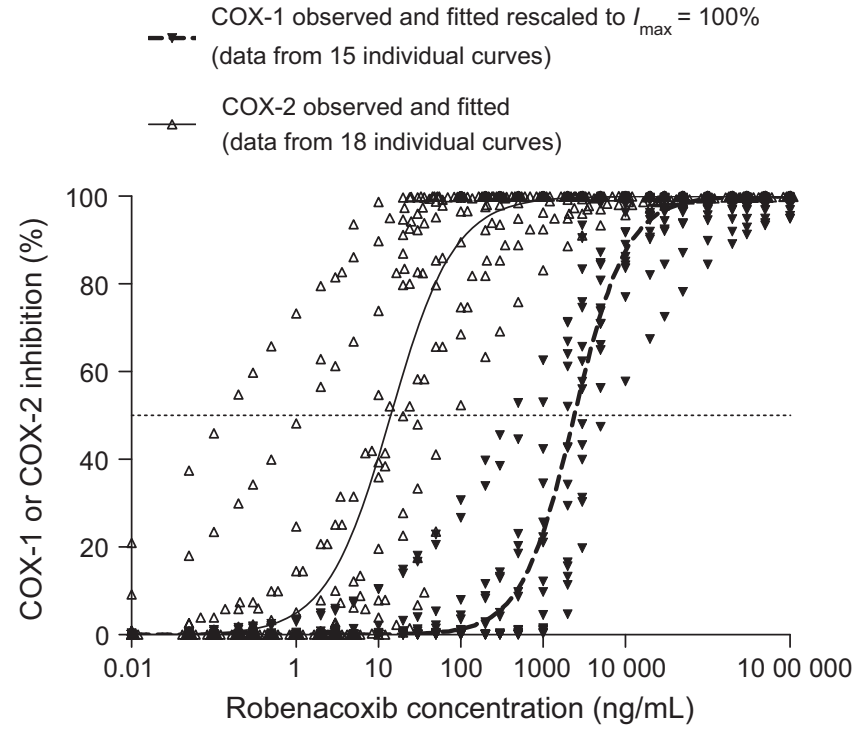

Fig. 6. Observed and fitted COX inhibition (\%) vs. robenacoxib concentration $(\mathrm{ng} / \mathrm{mL})$. COX-1 data were re-scaled to $100 \%$. In a naïve pooled data analysis, average regression curves for COX-1 and COX-2 were fitted with a sigmoid $I_{\max }$ model to all individual simulated curves (15 curves for COX-1 and 18 curves for COX-2).

administrations, reflecting similar MRTs for each route in exudate (Table 2) but much lower MRT in blood after intravenous compared to nonvascular administration routes. Consequently, it is concluded that the prolonged MRT of robenacoxib in exudate for all three administration routes is not attributable solely to passive diffusion and geometry of the tissue cage.

A more attractive hypothesis considers the binding of robenacoxib to a component of the inflammatory process (protein for example), with a subsequent local release. Indeed, creatinine is not extensively protein bound, whereas binding of
Table 4. Estimated PD parameters (mean and SD) describing the inhibitory effect of robenacoxib on serum $\mathrm{TxB}_{2}$ production after intravenous (eight cats) and subcutaneous administration (seven cats) of a nominal dose of $2 \mathrm{mg} / \mathrm{kg}$

\begin{tabular}{|c|c|c|}
\hline $\begin{array}{l}\text { Number of successful } \\
\text { modellings }\end{array}$ & $\begin{array}{c}\text { Intravenous } \\
\text { route } n=8 \text { out of } 8\end{array}$ & $\begin{array}{l}\text { Subcutaneous } \\
\text { route } n^{*}=7 \text { out of } 9\end{array}$ \\
\hline Parameters & Mean (SD) & Mean (SD) \\
\hline$I_{0}(\mathrm{ng} / \mathrm{mL})$ & $92.9(49.9)$ & $193.9(39.0)$ \\
\hline$T_{\min }(\mathrm{h})$ & $0.10(0.059)$ & $0.71(0.184)$ \\
\hline$R_{\min }(\mathrm{ng} / \mathrm{mL})$ & $20.5(19.13)$ & $106.5(41.64)$ \\
\hline $\mathrm{IC}_{50}(\mathrm{ng} / \mathrm{mL})$ & $2018(959-4245)$ & $2293(1426-3691)$ \\
\hline$n$ (no unit) & $1.6(0.8-3.2)$ & $2.4(1.1-5.3)$ \\
\hline$I_{\max }(\%)$ & $96.2(1.62)$ & $97.3(0.70)$ \\
\hline Delta $(\mathrm{ng} / \mathrm{mL})$ & $100.6(50.0)$ & $193.0(39.04)$ \\
\hline
\end{tabular}

Data were fitted using a sigmoid $I_{\max }$ for the fitting of subcutaneous dosing NA, non applicable. *Modelling failed in two cats for technical reasons (catheter and bad fitting). Delta, maximal $\mathrm{TxB}_{2}$ suppression in $\mathrm{ng} / \mathrm{mL}$; $I_{\text {max }}$, minimal achievable $\mathrm{TxB}_{2}$ concentration (expressed as a percentage relative to baseline concentration). Data after intravenous administration were weighted by the reciprocal of the predicted value. $T_{\min }$ and $R_{\min }$ : predicted time of occurrence of peak suppresion of serum $\mathrm{TxB}_{2}$ by robenacoxib and the corresponding minimal $\mathrm{TxB}_{2}$ value. $I_{0}$ : fitted value of baseline obtained from equation 13, taking into account the baseline drift in $\mathrm{TxB}_{2}$ concentrations observed with both placebo and robenacoxib treatments. $T_{\min }, I_{\max }$ and Delta presented as arithmetic mean (SD), $R_{\min }$, $\mathrm{IC}_{50}$ and $n$ as geometric mean [95\% confidence interval].

most NSAIDs, including robenacoxib, exceeds $98 \%$, and this is the most likely explanation for robenacoxib persistence in the tissue cage. A conclusion that the longer residence time of robenacoxib in exudate is, at least partially, owing to the high degree of drug binding to plasma protein and the leakage of the protein into exudate during the inflammatory process, rather than (or at least not solely) tissue cage kinetics and geometry, is further supported by the observation that exudate concentra- 
Table 5. Mean maximal effect, potency and selectivity of robenacoxib for the inhibition of COX-1 in 15 cats and COX-2 in 18 cats determined in vivo. Reported parameters and bounds of the 95\% confidence interval (95\% CI low and high) were calculated by naïve pooled data analysis

\begin{tabular}{|c|c|c|c|c|c|c|c|}
\hline PD parameters isoform & $I_{\max }(\%)$ & $\mathrm{IC}_{50}(\mathrm{ng} / \mathrm{mL})$ & $95 \%$ CI low & 95\% CI high & $n$ (no unit) & $95 \%$ CI low & 95\% CI high \\
\hline COX-1 isoenzyme & 96.8 & 2416 & 2244 & 2600 & 1.36 & 1.23 & 1.48 \\
\hline COX-2 isoenzyme & 100.0 & 14.1 & 12.5 & 16.0 & 1.12 & 0.98 & 1.25 \\
\hline
\end{tabular}

Reported parameters and bounds of the 95\% confidence interval (CI) (noted 95\% CI low and high) calculated with the so-called naive pooled data analysis (Giraudel et al., 2005a,b). Naive pooled approach: an average curve was fitted with a sigmoid $I_{\text {max }}$ model to all simulated curves (15 for COX-1 and 18 for COX-2) as if they were data from a single individual.

Table 6. Three categories of indices to describe the in vivo selectivity of robenacoxib as determined by simultaneous fitting of individual inhibition values from COX-1 assay in 15 cats and COX-2 assay in 18 cats (so-called naïve pooled data analysis)

\begin{tabular}{|c|c|c|}
\hline & $\begin{array}{l}\text { Present } \\
\text { study }\end{array}$ & $\begin{array}{c}\text { Giraudel } \\
\text { et al., 2009a,b }\end{array}$ \\
\hline \multicolumn{3}{|c|}{ Classical selectivity ratios $\left(\mathrm{IC}_{X} \mathrm{COX}-1 / \mathrm{IC}_{X} \mathrm{COX}-2\right)$} \\
\hline $\mathrm{IC}_{50} / \mathrm{IC}_{50}$ & 170.9 & 502.3 \\
\hline $\mathrm{IC}_{80} / \mathrm{IC}_{80}$ & 137.2 & 477.7 \\
\hline $\mathrm{IC}_{95} / \mathrm{IC}_{95}$ & 107.1 & 451.6 \\
\hline $\mathrm{IC}_{99} / \mathrm{IC}_{99}$ & 82.5 & 425.4 \\
\hline \multicolumn{3}{|c|}{ Other selectivity ratios $\left(\mathrm{IC}_{X} \mathrm{COX}-1 / \mathrm{IC}_{Y} \mathrm{COX}-2\right)$} \\
\hline $\mathrm{IC}_{1} / \mathrm{IC}_{99}$ & 0.1 & 0.01 \\
\hline $\mathrm{IC}_{5} / \mathrm{IC}_{95}$ & 1.4 & 0.38 \\
\hline $\mathrm{IC}_{10} / \mathrm{IC}_{90}$ & 4.7 & 2.36 \\
\hline $\mathrm{IC}_{20} / \mathrm{IC}_{80}$ & 17.82 & 17.05 \\
\hline \multicolumn{3}{|c|}{$\%$ Inhibition of COX-1 for a fixed \% inhibition of COX-2 (0-100\%) } \\
\hline$\%$ Inhibition of $\mathrm{COX}-1$ for $\mathrm{IC}_{50} \mathrm{COX}-2$ & 0.09 & 0.56 \\
\hline$\%$ Inhibition of $\mathrm{COX}-1$ for $\mathrm{IC}_{80} \mathrm{COX}-2$ & 0.5 & 2.31 \\
\hline$\%$ Inhibition of COX-1 for $\mathrm{IC}_{90} \mathrm{COX}-2$ & 1.32 & 5.17 \\
\hline$\%$ Inhibition of COX-1 for $\mathrm{IC}_{95} \mathrm{COX}-2$ & 3.21 & 10.52 \\
\hline$\%$ Inhibition of $\mathrm{COX}-1$ for $\mathrm{IC}_{99} \mathrm{COX}-2$ & 19.81 & 39.17 \\
\hline
\end{tabular}

Three sets of data, obtained by naive pooled approach are reported for the present study. For comparison, values from in vitro assays reported in Giraudel et al., 2009a,b (calculated with a nonlinear parametric mixed effect model).

tions were higher than transudate (noninjected cages) concentrations for several NSAIDs in a range of species (Landoni \& Lees, 1995; Lees et al., 1996, 2004; Arifah et al., 2003). The carrageenan-stimulated tissue cage model was designed to mimic acute joint inflammation or a sterile abscess, and has been described as a deep peripheral compartment (Clarke et al., 1989). According to this view, the slow release of robenacoxib from exudate protein could be a critical factor explaining a long residence time of robenacoxib in the cage or any closed anatomical location, such as an inflamed joint. This is contrary to the classical in vivo situation, where protein binding does not act as a drug reservoir that controls free local drug concentration (Toutain \& Bousquet-Melou, 2002).

Comparison with other NSAIDs in other species. Similar differences in residence time between plasma and an inflamed compartment were demonstrated for lumiracoxib distribution between plasma and synovial fluid (Scott et al., 2004). Lumiracoxib is a structural analogue of robenacoxib with a plasma elimination half-life of $6.5 \mathrm{~h}$. In human subjects, lumiracoxib concentrations were approximately three times higher in the synovial fluid of patients with arthritis, compared with plasma (Scott et al., 2004). Owens et al. (1994) reported that ketoprofen concentrations in the synovial fluid of a carrageenan-inflamed equine intercarpal joint were six times higher than in a noninflamed joint. Robenacoxib MRT was longer in tissue cages after zymosan stimulation in rats (King et al., 2009). The tissue cage model may have a predictive role in joint disease, as the residence time of robenacoxib in the canine stifle was also longer in inflamed joint synovial fluid (both experimental urate crystalinduced synovitis and naturally occurring osteoarthritis) compared with noninflamed synovial fluid or blood (Silber et al., 2010). It would have been relevant to compare the MRT of robenacoxib in feline tissue cage exudate and inflamed synovial fluid but this was too technically challenging. Robenacoxib and lumiracoxib belong to a particular family of COXibs presenting a carboxylic acidic group (pKa: 4.0-4.7), instead of a methylsulfone (as for rofecoxib and firocoxib) or sulphonamide group (as for celecoxib and deracoxib). This difference could explain both their short blood half-life and their capacity to remain in inflamed tissue (Brune \& Furst, 2007), conferring on them tissue selectivity as well as enzyme selectivity.

Thus, whilst tissue accumulation is, in part, model dependent, it is nevertheless likely that some short elimination halflife NSAIDs will accumulate in deep compartments and this may be exacerbated when such compartments are acutely inflamed. Such PK factors may explain the negative hysteresis described after robenacoxib administration, but the model is also amenable for PK-PD modelling, as it allows exploration of the concentration-effect relationship in exudate. A high potency for COX-2 inhibition in peripheral tissue is the second factor accounting for more prolonged enzyme inhibition than would be predicted from plasma or blood PK profiles.

\section{Potency ratio and selectivity of robenacoxib}

Based on the present results, mean $\mathrm{IC}_{50} \mathrm{COX}-1$ and $\mathrm{IC}_{50} \mathrm{COX}-2$ values were $2416 \mathrm{ng} / \mathrm{mL} \quad(7.38 \mu \mathrm{M})$ and $14.1 \mathrm{ng} / \mathrm{mL}$ $(0.043 \mu \mathrm{M})$, respectively. The $\mathrm{IC}_{50} \mathrm{COX}-1 / \mathrm{IC}_{50} \mathrm{COX}-2$ ratio, obtained from our in vivo data, was 171:1. In feline whole-blood assays, the robenacoxib potency inhibition ratio (COX-1:COX-2) was 502.3:1 (Giraudel et al., 2009b). The corresponding $\mathrm{IC}_{50}$ COX-2 of $19 \mathrm{ng} / \mathrm{mL}(0.058 \mu \mathrm{M})$ was similar to our results, 
especially in view of the differing experimental protocol and models. This similarity adds to the confidence in the ability of the tissue cage model to generate valid potency values for COX-2 inhibition. On the other hand, the $\mathrm{IC}_{50}$ for COX-1 of $9458 \mathrm{ng} / \mathrm{mL}$ was nearly fourfold higher than our value. We observed a short-lasting inhibition of COX-1, at concentrations lower than Giraudel et al. (2009a,b). Another robenacoxib whole-blood assay reported $\mathrm{IC}_{50}$ COX-1 of $1630 \mathrm{ng} / \mathrm{mL}$ $(4.98 \mu \mathrm{M})$ and $\mathrm{IC}_{50} \mathrm{COX}-2$ of $36.3 \mathrm{ng} / \mathrm{mL}(0.111 \mu \mathrm{M})$, respectively, yielding an $\mathrm{IC}_{50} \mathrm{COX}-1: \mathrm{IC}_{50} \mathrm{COX}-2$ of 40.3:1 (Schmid et al., 2010). The difference between the whole-blood assay results could be accounted for by the fact that the laboratories and techniques were different and even minor methodological changes can alter $\mathrm{IC}_{50}$ values (Warner et al., 1999; Lees et al., 2004). Robenacoxib is extensively bound to plasma protein $(99.9 \%$ in rats and $99.7 \%$ in dogs at $50 \mathrm{ng} / \mathrm{mL}$ ) (King et al., 2009) but binding of robenacoxib to exudate protein was not measured. We can postulate, however, that the binding in exudate is similar to serum, as lumiracoxib protein binding was similar in plasma and inflamed synovial fluid (Scott et al., 2004). The PK/PD modelling was carried out in exudate based on total exudate robenacoxib concentration. Therefore, results could be compared with plasma concentrations in whole-blood assays.

The model used to describe the exudate data may influence the estimation of $\mathrm{IC}_{50} \mathrm{~s}$, as illustrated for ketoprofen $\mathrm{IC}_{50}$ estimations obtained in exudate from several species (Lepist \& Jusko, 2004). An indirect response model may provide a better mechanistic understanding of inflammation dynamics than the $E_{\text {max }}$ model with $K_{\text {eo }}$ (effect compartment model). An indirect response model was used successfully to characterize naproxen $\mathrm{IC}_{50}$ in acute carrageenan inflammation in the rat (Josa et al., 2001). The drift in serum $\mathrm{TxB}_{2}$ concentrations with time was documented in previous publications (Lees et al., 1987). Experimental conditions may play a role in this drift, e.g. the vascular catheter, presence in the circulation of very low concentrations of heparin, stress and recovery from anaesthesia. Alternatively or possibly additionally, a true physiological oscillating or circadian release of prostanoids may occur. Discounting a change of baseline in the analysis of the concentration-effect relationship during placebo administration would introduce error to estimates of potency and maximum effect of robenacoxib (Ollerstam et al., 2006). For this reason, simultaneous modelling of placebo and treatment data is more robust than comparison relative to baseline of data obtained after treatment.

The present data confirmed the high COX-2 selectivity of robenacoxib in vivo on the basis of the $\mathrm{IC}_{50}$ ratio, but the slopes of curves for COX-1 and COX-2 determine their shapes and parallelism. The data predicted that less than $1 \%$ of $\mathrm{COX}-1$ activity would be inhibited for a clinically relevant 80-90\% inhibition of COX-2. This result was consistent with the prediction of up to $5 \%$ inhibition in whole-blood assays (Giraudel et al., $2009 \mathrm{~b}$ ) and is likely to contribute to the potentially superior gastro-intestinal safety of COXibs. In comparison, COX-1 inhibition in serum persisted for up to $24 \mathrm{~h}$ with ketoprofen (Lees et al., 2003), carprofen (Taylor et al., 1996) and meloxicam (Schmid et al., 2010) administered at clinical dosages in the cat.
With COX-1-sparing drugs, the incidence of GI adverse effects in man was decreased but not eliminated (Bombardier et al., 2000). Cyclooxygenase may play a role in mucosal protection and healing of gastric ulcers. Moreover, COX-2 expression is increased at the edges of gastric ulcers, where it indirectly accelerates ulcer healing by increasing angiogenesis (Jones et al., 1999). In a canine gastric mucosal healing model, COX-2 inhibition by firocoxib reduced ulcer healing in comparison with placebo and tepoxalin by a prostaglandin-independent mechanism (Goodman et al., 2009).

\section{CONCLUSION}

Despite rapid clearance from blood after intravenous, subcutaneous or oral administration, robenacoxib $(2 \mathrm{mg} / \mathrm{kg})$ inhibition of COX-2 in exudate persisted for $24 \mathrm{~h}$. A tissue cage model of acute inflammation was used to determine robenacoxib's PK and its in vivo and ex vivo selectivity for COX-1 and COX-2 using serum $\mathrm{TxB}_{2}$ and exudate $\mathrm{PGE}_{2}$, respectively, as surrogate markers of activity. Potency ratio $\mathrm{IC}_{50} \mathrm{COX} 1: \mathrm{IC}_{50} \mathrm{COX} 2$ was $171: 1$, and slopes of the concentration-effect relationship were 1.36 and 1.12 for COX-1 and COX-2, respectively. This work highlights the isoenzyme and tissue selectivity of robenacoxib and supports the current recommendation of once-daily administration.

\section{ACKNOWLEDGMENTS AND DISCLOSURE}

This study was supported by BBSRC and Novartis Animal Health by a CASE award to L.P. Professor Lees and Professor Elliott have acted as consultants for several drug companies, including Novartis Animal Health.

\section{REFERENCES}

Arifah, A.K., Landoni, M.F. \& Lees, P. (2003) Pharmacodynamics, chiral pharmacokinetics and PK-PD modelling of ketoprofen in the goat. Journal of Veterinary Pharmacology Therapeutics, 26, 139-150.

Bombardier, C., Laine, L., Reicin, A., Shapiro, D., Burgos-Vargas, R., Davis, B., Day, R., Ferraz, M.B., Hawkey, C.J., Hochberg, M.C., Kvien, T.K. \& Schnitzer, T.J. (2000) Comparison of upper gastrointestinal toxicity of rofecoxib and naproxen in patients with rheumatoid arthritis. VIGOR Study Group. New England Journal of Medicine, 343, 1520-1528.

Brune, K. \& Furst, D.E. (2007) Combining enzyme specificity and tissue selectivity of cyclooxygenase inhibitors: towards better tolerability? Rheumatology (Oxford), 46, 911-919.

Clarke, C.R., Short, C.R., Bourne, D.W. \& Usenik, E.A. (1989) Subcutaneously implanted tissue chambers - a pharmacokinetic study. Journal of Veterinary Pharmacology Therapeutics, 12, 312-321.

Dayneka, N.L., Garg, V. \& Jusko, W.J. (1993) Comparison of four basic models of indirect pharmacodynamic responses. Journal of Pharmacokinetics and Biopharmaceutics, 21, 457-478.

Elliott, J. \& Barber, P. (1998) Feline chronic renal failure: clinical findings in 80 cases diagnosed between 1992 and 1995. Journal of Small Animal Practice, 39, 78-85. 
Giraudel, J.M., Diquelou, A., Laroute, V., Lees, P. \& Toutain, P.L. (2005a) Pharmacokinetic/pharmacodynamic modelling of NSAIDs in a model of reversible inflammation in the cat. British Journal of Pharmacology, 146, 642-653.

Giraudel, J.M., Diquelou, A., Lees, P. \& Toutain, P.L. (2005b) Development and validation of a new model of inflammation in the cat and selection of surrogate endpoints for testing anti-inflammatory drugs. Journal of Veterinary Pharmacology Therapeutics, 28, 275-285.

Giraudel, J.M., King, J.N., Jeunesse, E.C., Lees, P. \& Toutain, P.L. (2009a) Use of a pharmacokinetic/pharmacodynamic approach in the cat to determine a dosage regimen for the COX-2 selective drug robenacoxib. Journal of Veterinary Pharmacology Therapeutics, 32, 18-30.

Giraudel, J.M., Toutain, P.L., King, J.N. \& Lees, P. (2009b) Differential inhibition of cyclooxygenase isoenzymes in the cat by the NSAID robenacoxib. Journal of Veterinary Pharmacology Therapeutics, 32, 3140 .

Giraudel, J.M., Gruet, P., Alexander, D., Seewald, W. \& King, J.N. (2010) Oral robenacoxib versus ketoprofen for the treatment of acute pain and inflammation associated with musculo-skeletal disorders in cats: a randomized, non-inferiority field trial. American Journal of Veterinary Research, 71, 710-719.

Goodman, L., Torres, B., Punke, J., Reynolds, L., Speas, A., Ellis, A. \& Budsberg, S. (2009) Effects of firocoxib and tepoxalin on healing in a canine gastric mucosal injury model. Journal of Veterinary Internal Medicine, 23, 56-62.

Higgins, A.J. \& Lees, P. (1984) Arachidonic acid metabolites in carrageenin-induced equine inflammatory exudate. Journal of Veterinary Pharmacology Therapeutics, 7, 65-72.

Jones, M.K., Wang, H., Peskar, B.M., Levin, E., Itani, R.M., Sarfeh, I.J. \& Tarnawski, A.S. (1999) Inhibition of angiogenesis by nonsteroidal anti-inflammatory drugs: insight into mechanisms and implications for cancer growth and ulcer healing. Nature Medicine, 5, 14181423 .

Josa, M., Urizar, J.P., Rapado, J., Dios-Vieitez, C., Castaneda-Hernandez, G., Flores-Murrieta, F., Renedo, M.J. \& Troconiz, I.F. (2001) Pharmacokinetic/pharmacodynamic modeling of antipyretic and antiinflammatory effects of naproxen in the rat. Journal of Pharmacology and Experimental Therapeutics, 297, 198-205.

Jung, M., Lees, P., Seewald, W. \& King, J.N. (2009) Analytical determination and pharmacokinetics of robenacoxib in the dog. Journal of Veterinary Pharmacology Therapeutics, 32, 41-48.

Kelley, M. \& DeSilva, B. (2007) Key elements of bioanalytical method validation for macromolecules. American Association of Pharmaceutical Scientists Journal, 9, E156-E163.

King, J.N., Dawson, J., Esser, R.E., Fujimoto, R., Kimble, E.F., Maniara, W., Marshall, P.J., O’Byrne, L., Quadros, E., Toutain, P.L. \& Lees, P. (2009) Preclinical pharmacology of robenacoxib: a novel selective inhibitor of cyclooxygenase-2. Journal of Veterinary Pharmacology Therapeutics, 32, 1-17.

Kristensen, M. \& Hansen, T. (2004) Statistical analyses of repeated measures in physiological research: a tutorial. Advances in Physiology Education, 28, 2-14.

Landoni, M.F. \& Lees, P. (1995) Comparison of the anti-inflammatory actions of flunixin and ketoprofen in horses applying PK/PD modelling. Equine Veterinary Journal, 27, 247-256.

Lascelles, B.D. (2010) Feline degenerative joint disease. Veterinary Surgery, 39, 2-13.

Lascelles, B.D., Court, M.H., Hardie, E.M. \& Robertson, S.A. (2007) Nonsteroidal anti-inflammatory drugs in cats: a review. Veterinary Anaesthesia and Analgesia, 34, 228-250.

Lees, P., Ewins, C.P., Taylor, J.B. \& Sedgwick, A.D. (1987) Serum thromboxane in the horse and its inhibition by aspirin, phenylbutazone and flunixin. British Veterinary Journal, 143, 462-476.
Lees, P., Delatour, P., Foster, A.P., Foot, R. \& Baggot, D. (1996) Evaluation of carprofen in calves using a tissue cage model of inflammation. British Veterinary Journal, 152, 199-211.

Lees, P., Taylor, P.M., Landoni, F.M., Arifah, A.K. \& Waters, C. (2003) Ketoprofen in the cat: pharmacodynamics and chiral pharmacokinetics. Veterinary Journal, 165, 21-35.

Lees, P., Landoni, M.F., Giraudel, J. \& Toutain, P.L. (2004) Pharmacodynamics and pharmacokinetics of nonsteroidal anti-inflammatory drugs in species of veterinary interest. Journal of Veterinary Pharmacology Therapeutics, 27, 479-490.

Lepist, E.I. \& Jusko, W.J. (2004) Modeling and allometric scaling of s(+)ketoprofen pharmacokinetics and pharmacodynamics: a retrospective analysis. Journal of Veterinary Pharmacology Therapeutics, 27, 211-218.

Littell, R.C., Henry, P.R. \& Ammerman, C.B. (1998) Statistical analysis of repeated measures data using SAS procedures. Journal of Animal Science, 76, 1216-1231.

Nantel, F., Denis, D., Gordon, R., Northey, A., Cirino, M., Metters, K.M. \& Chan, C.C. (1999) Distribution and regulation of cyclooxygenase-2 in carrageenan-induced inflammation. British Journal of Pharmacology, 128, 853-859.

Ollerstam, A., Visser, S.A., Persson, A.H., Eklund, G., Nilsson, L.B., Forsberg, T., Wiklund, S.J., Gabrielsson, J., Duker, G. \& Al-Saffar, A. (2006) Pharmacokinetic-pharmacodynamic modeling of drug-induced effect on the QT interval in conscious telemetered dogs. Journal of Pharmacological and Toxicological Methods, 53, 174-183.

Owens, J.G., Kammerling, S.G. \& Keowen, M.L. (1994) Anti-inflammatory effects and pharmacokinetics of ketoprofen in a model of equine synovitis. In Proceedings of the 6th International Congress of the EAVPT Ed. P. Lees, pp. 170-171. Blackwell Scientific Publications, Oxford.

Pelligand, L., House, A.K., Summers, B.A., Hatzis, A., Tivers, M., Elliott, J. \& Lees, P. (2011) Development and validation of a tissue cage model of acute inflammation in the cat. Journal of Veterinary Pharmacology Therapeutics, in press.

Schmid, V.B., Seewald, W., Lees, P. \& King, J.N. (2010) In vitro and ex vivo inhibition of COX isoforms by robenacoxib in the cat: a comparative study. Journal of Veterinary Pharmacology Therapeutics, 33, 444-452.

Scott, G., Rordorf, C., Reynolds, C., Kalbag, J., Looby, M., Milosavljev, S., Weaver, M., Huff, J.P. \& Ruff, D.A. (2004) Pharmacokinetics of lumiracoxib in plasma and synovial fluid. Clinical Pharmacokinetics, 43, 467-478.

Sidhu, P., Shojaee Aliabadi, F., Andrews, M. \& Lees, P. (2003) Tissue chamber model of acute inflammation in farm animal species. Research in Veterinary Science, 74, 67-77.

Silber, H., Burgener, C., Letellier, I.M., Peyrou, M., Jung, M., King, J.N., Gruet, P. \& Giraudel, J. (2010) Population pharmacokinetic analysis of blood and joint synovial fluid concentrations of robenacoxib from healthy dogs and dogs with osteoarthritis. Pharmaceutical Research, 27, 2633-2645

Taylor, P.M. \& Robertson, S.A. (2004) Pain management in cats - past, present and future. Part 1. The cat is unique. Journal of Feline Medicine and Surgery, 6, 313-320.

Taylor, P.M., Delatour, P., Landoni, F.M., Deal, C., Pickett, C., Shojaee Aliabadi, F., Foot, R. \& Lees, P. (1996) Pharmacodynamics and enantioselective pharmacokinetics of carprofen in the cat. Research in Veterinary Science, 60, 144-151.

Tomlinson, A., Appleton, I., Moore, A.R., Gilroy, D.W., Willis, D., Mitchell, J.A. \& Willoughby, D.A. (1994) Cyclo-oxygenase and nitric oxide synthase isoforms in rat carrageenin-induced pleurisy. British Journal of Pharmacology, 113, 693-698.

Toutain, P.L. \& Bousquet-Melou, A. (2002) Free drug fraction vs free drug concentration: a matter of frequent confusion. Journal of Veterinary Pharmacology Therapeutics, 25, 460-463. 
Toutain, P.L. \& Lees, P. (2004) Integration and modelling of pharmacokinetic and pharmacodynamic data to optimize dosage regimens in veterinary medicine. Journal of Veterinary Pharmacology Therapeutics, 27, 467-477.

Viswanathan, C.T., Bansal, S., Booth, B., DeStefano, A.J., Rose, M.J., Sailstad, J., Shah, V.P., Skelly, J.P., Swann, P.G. \& Weiner, R. (2007) Quantitative bioanalytical methods validation and implementation: best practices for chromatographic and ligand binding assays. Pharmaceutical Research, 24, 1962-1973.

Wallace, J.L., Chapman, K. \& McKnight, W. (1999) Limited anti-inflammatory efficacy of cyclo-oxygenase-2 inhibition in carra- geenan-airpouch inflammation. British Journal of Pharmacology, 126, 1200-1204.

Warner, T.D., Giuliano, F., Vojnovic, I., Bukasa, A., Mitchell, J.A. \& Vane, J.R. (1999) Nonsteroid drug selectivities for cyclo-oxygenase-1 rather than cyclo-oxygenase- 2 are associated with human gastrointestinal toxicity: a full in vitro analysis. Proceedings of the National Academy of Sciences US A, 96, 7563-7568.

Yamaoka, K., Nakagawa, T. \& Uno, T. (1978) Application of Akaike's information criterion (AIC) in the evaluation of linear pharmacokinetic equations. Journal of Pharmacokinetics and Biopharmaceutics, 6, 165175 . 